\title{
Dosimetric evaluation and systematic review of radiation therapy techniques for early stage node- negative breast cancer treatment
}

This article was published in the following Dove Press journal:

Cancer Management and Research

\author{
Tabitha Y Chan' \\ Johann I Tang' \\ Poh Wee Tan' \\ Neill Roberts ${ }^{2}$ \\ 'Department of Radiation Oncology, \\ National University Cancer Institute, \\ Singapore, Singapore; ${ }^{2}$ Faculty of \\ Health and Wellbeing, Sheffield Hallam \\ University, Sheffield, UK
}

\begin{abstract}
Radiation therapy (RT) is essential in treating women with early stage breast cancer. Early stage node-negative breast cancer (ESNNBC) offers a good prognosis; hence, late effects of breast RT becomes increasingly important. Recent literature suggests a potential for an increase in cardiac and pulmonary events after RT. However, these studies have not taken into account the impact of newer and current RT techniques that are now available. Hence, this review aimed to evaluate the clinical evidence for each technique and determine the optimal radiation technique for ESNNBC treatment. Currently, six RT techniques are consistently used and studied: 1) prone positioning, 2) proton beam RT, 3) intensity-modulated RT, 4) breathhold, 5) partial breast irradiation, and 6) intraoperative RT. These techniques show dosimetric promise. However, limited data on late cardiac and pulmonary events exist due to challenges in long-term follow-up. Moving forward, future studies are needed to validate the efficacy and clinical outcomes of these current techniques.
\end{abstract}

Keywords: early stage, breast cancer, radiation technique, dosimetric

\section{Introduction}

An early stage node-negative breast cancer (ESNNBC) offers a good prognosis. ${ }^{1}$ Improved surgical techniques, systemic therapy options, and radiation therapy (RT) have resulted in significant improvement in long-term cause-specific survival. ${ }^{2,3}$

Increasing use of RT has resulted in significant increase in long-term survival, ${ }^{2,3}$ translating to more women at risk of developing long-term treatment-related toxicities. Hence, it is contradictory that the benefits of improved survival, due to the successful delivery of RT for ESNNBC, are negated by RT-induced toxicities.

Dosimetry planning for whole breast external beam radiotherapy (WBEBRT) typically involves a pair of tangential fields to homogenously treat the entire breast while avoiding adjacent vital organs, like the lungs, heart, and left anterior descending artery $(\mathrm{LAD}){ }^{4}$

Cardiac toxicity studies demonstrate increased mortality and morbidity from heart disease, ${ }^{5-8}$ especially left-sided WBEBRT patients, $10-15$ years after receiving irradiation compared to right-sided WBEBRT patients. Recent imaging studies demonstrate consistent occurrence of perfusion defects, microvascular disease, stenosis, and atherosclerosis where the heart and coronary arteries are included in the radiation field and validate the need to reduce cardiac dose. ${ }^{6,7,9}$

Lung toxicity studies have demonstrated increased risk of secondary lung cancers and mortality for radiation-induced lung cancer post WBEBRT. ${ }^{5}$ Grantzau and Overgaard found that $\geq 5$ years after breast cancer diagnosis, RT was significantly associ-
Correspondence: Tabitha Y Chan Department of Radiation Oncology, National University Cancer Institute, Singapore, 5 Lower Kent Ridge Road,

I1 19074, Singapore

Tel +6567728381

Fax +6567342986

Email tabitha_chan@nuhs.edu.sg 
ated with an increased risk of radiation-induced lung cancer relative risk (RR) of 1.39 (95\% CI 1.28-1.51). ${ }^{10}$

Radiation pneumonitis (RP) arises from irradiation of the adjacent ipsilateral lung in breast cancer. It has been reported to be related to 1) the amount of lung irradiated within the tangential fields, 2) use of supraclavicular field, 3) prior exposure to chemotherapy, 4) high-dose chemotherapy, and 5) concurrent tamoxifen medication and smoking habits. ${ }^{11}$

Current literature suggests new advanced radiation techniques vis-a-vis delivering and quantifying radiation doses to the organs at risk (OAR). ${ }^{12}$ Such techniques include 1) maneuvers to achieve maximum separation of the heart from the chest wall (ie, synchronizing RT with the patients' respiratory cycle or prone positioning), ${ }^{13-15} 2$ ) designing and utilizing cardiac blocks to minimize radiation damage to the heart while avoiding over shielding, ${ }^{16} 3$ ) utilizing advanced technologies for RT delivery (ie, intensity-modulated radiation therapy [IMRT] or proton beam radiation therapy [PBT]), ${ }^{17,18}$ and (4) moving away from whole breast volume to partial breast volume treatment (accelerated partial breast irradiation [APBI] or intraoperative radiation therapy [IORT]). ${ }^{19,20}$

This review aimed to evaluate the evidence for each technique by 1) identifying the different breast RT techniques for ESNNBC, 2) collate the dosimetric outcomes for each breast RT technique, and 3) identify the best dosimetric technique.

\section{Methods}

Eligible articles include articles about 1) breast cancer RT; 2) RT-associated toxicities, and 3) published in an English language peer-reviewed journal. A systematic search using MEDLINE/PubMed and MeSH headings was used to identify articles addressing RT techniques. The headings were breast cancer, radiation therapy, intensity modulated, prone, partial breast, breath-hold $(\mathrm{BH})$, gating, intraoperative, side effects, heart, cardiac, lung, and pulmonary.

Articles were excluded if they provided pilot data, descriptions of a study design, articles on non-breast cancer data, post-mastectomy radiation, lymph node irradiation, exclusive evaluation of patients with pectus excavatum, bilateral breast irradiation, articles not having heart, LAD, and/or lung dosimetric data or non-English language articles.

Articles were reviewed specifically for data from patients whose left breast was treated. For dosimetric studies, mandatory information included the sample size, techniques used, and outcomes. For clinical studies, mandatory information included sample size reviewed, RT techniques utilized, whether there was a comparison arm, and clinical outcomes (recurrence, toxicities, and pulmonary and/or cardiac outcomes).

Given heterogeneity among studies, OAR dosimetric parameters were evaluated through three different mechanisms. For lung, these mechanisms are 1) anatomic data (ie, volume of lung within irradiated field) and 2) lung dose volume histogram $(\mathrm{DVH})$ data $\left(\mathrm{V}_{\mathrm{x}}\right.$ and $\left.\mathrm{D}_{\mathrm{x}}\right)$. For heart, these mechanisms are 1) anatomic data (ie, volume of heart within irradiated field) and 2) heart DVH data $\left(\mathrm{V}_{\mathrm{x}}\right.$ and $\left.\mathrm{D}_{\mathrm{x}}\right)$. For LAD, 1) anatomic data (ie, volume of LAD within irradiated field) and 2) LAD DVH data $\left(\mathrm{V}_{\mathrm{x}}\right.$ and $\left.\mathrm{D}_{\mathrm{x}}\right)$.

All searches were completed by June 10, 2017.

\section{Results}

Six consistently utilized and studied RT techniques were found: 1) prone positioning, 2) PBT, 3) IMRT, 4) $\mathrm{BH}, 5$ ) partial breast irradiation (PBI), and 6) IORT.

Table 1 summarizes the mechanism of each RT technique. Table 2 presents the data supporting each technique and the key dosimetric findings.

\section{Prone technique}

The prone position is a technique where the patient lies on a platform with a modifiable aperture through which the ipsilateral breast hangs away from the thorax by gravity. ${ }^{21}$

\section{Lung exposure when lying prone}

Literature demonstrates a significant decrease in lung dose in the prone position although the left lung volume was essentially greater in the prone position. ${ }^{22-26}$ The breast sits

Table I RT techniques

\begin{tabular}{ll}
\hline RT technique & Mechanism of technique \\
\hline Prone positioning & Breast falls away from the chest wall thereby increasing the distance of the OARs to the RT beam \\
Proton beam therapy & Unlike the properties of photons, protons allow for a steep dose fall off \\
Intensity-modulated RT & Utilizing dose planning algorithms and computerizing each individual leaf position of the multileaf \\
& collimator to shape the radiation field away from the OARs \\
Breath-hold & Utilizing respiratory inspiration to achieve maximum separation from heart to chest wall \\
Partial breast irradiation & Smaller target volume theoretically decreases OAR dose \\
Intraoperative RT & Smaller target volume and sometimes utilizing lower energies to reduce OAR dose
\end{tabular}

Abbreviations: RT, radiation therapy; OAR, organ at risk. 
anterior to the lung when the patient is lying prone. This subjects it to the compressive force from the weight of the breast. Lying prone prevents this compression, leading to better expansion of the lung. ${ }^{27}$ Hence, the decrease in lung dose could be attributed to an increase in the lung volume when lying prone. All prone treatment techniques showed similar lung dose metrics.

This correlates to decreased lung exposure and possibly reduces the risk of radiation-induced lung toxicities. While conventional WBERT in the supine position has been shown to increase the risk of ipsilateral lung carcinoma with a RR of $0.11,{ }^{28}$ lying prone could reduce this RR.

\section{Cardiac and LAD exposure when lying prone}

With the breast parenchyma falling away from the chest wall, this allows the radiation beam edge to be potentially placed further away from the heart. This increases the heart to chest wall distance and theoretically allows for cardiac dose reduction. ${ }^{20,29}$

NYU trial studied both the supine and prone positions and found that $85 \%$ of the patients with left breast target lesions demonstrated a reduction of in-field heart volume by a mean of $11 \mathrm{cc} .{ }^{30} \mathrm{~A}$ recent similar trial, consisting of 53 patients with left breast cancer also demonstrated similar results where $87 \%$ had a $12 \mathrm{cc}$ mean reduction of in-field heart volume. ${ }^{22}$ However, the reduction of in-field heart volume due to the prone technique is an inconsistent finding as a comparatively small percentage of patients still benefit from the supine position compared to the prone position. ${ }^{22,30,31}$

Kirby et al found an increase in heart dose in eight of 30 patients receiving whole breast irradiation, with a median increase in $\mathrm{LAD}_{\text {mean }}$ of $9.5 \mathrm{~Gy} .{ }^{24}$ Mulliez et al analyzed supine vs prone plans for 18 patients. ${ }^{32}$ The results demonstrated no significant improvement in heart sparing with the prone position. Würschmidt et al suggested that cardiac and LAD exposure might inadvertently increase due to the anterior movement of the heart when lying prone for WBEBRT. ${ }^{33}$ There was no difference in the mean heart dose for left WBEBRT in the prone (4.16 Gy, 95\% CI 3.5-4.9 Gy) and supine positions (4.01 Gy; 95\% CI 3.4-4.6 Gy; $P=0.7$ ). However, the $\mathrm{LAD}$ received a significantly higher mean dose and no improvement in the maximum dose in the prone position. For the left breast prone WBEBRT, the LAD received a significantly higher average mean dose (33.5 Gy; 95\% CI 29.5-37.4 Gy) compared to left supine WBEBRT (25.6 Gy; 95\% CI 21.4-29.7 Gy; $P=0.0051)$. The average mean maximum dose was comparable $(P=0.766)$ between supine WBEBRT (43.2 Gy; 95\% CI 39.14-47.19 Gy) and prone WBEBRT (43.9 Gy; 95\% CI 40.73-47 Gy).
Hence, cardiac and coronary artery benefits for prone position remains controversial with conflicting results. ${ }^{22,29,30,33-35}$ This could be due to varying contouring and treatment techniques among the different institutions.

\section{Concerns regarding the prone technique}

Concerns regarding decreased reproducibility of the prone position and poor set up from patient discomfort may lead to greater potential for increased dose to normal tissues. ${ }^{20,36}$ However, Jozsef et al demonstrated that reproducibility of the prone position is improved with cone beam $\mathrm{CT} .{ }^{37}$ This is at the expense of additional irradiation. ${ }^{38}$

While early studies postulate poorer cosmetic outcomes with the prone technique from risk of erythema, recent research have proven comparable or better outcomes compared to the supine technique. ${ }^{23,39,40}$

Stegman et al conducted the largest long-term study with a cohort of 245 patients and a median follow-up of 4.9 years. ${ }^{41}$ The prone position resulted in similar long-term disease control with a favorable toxicity profile compared with standard supine tangents. However, it can only be postulated that the anatomic advantage of prone positioning may contribute to improving the therapeutic ratio of post-lumpectomy radiation by improving dose homogeneity and minimizing incidental cardiac and lung dose. Long-term follow-up studies evaluating cardiac and pulmonary outcomes are needed.

\section{Current scenario}

Although the evidence for lung sparing is clear, the value of cardiac and LAD sparing remains equivocal. Subset analyses suggest large-breasted patient generally benefit more from the prone position compared to small-breasted patients. ${ }^{40,41}$

\section{PBT}

The potential of PBT lies in its unique physical dose-deposition properties that allow maximum dose deposition within the tumor and rapid dose fall off beyond the Bragg peak. This potentially reduces adjacent OARs and subsequently toxicities incurred. ${ }^{42-45}$

\section{Lung, heart, and LAD exposure when utilizing PBT}

Dosimetric studies demonstrate dose reduction to the OARs. ${ }^{42,43,45}$ Lin et al demonstrated significant reductions to high and low doses to the lung, heart, and LAD where lung $\mathrm{V}_{20 \text { Gy }}$ (photon vs proton: $12.5 \%$ vs $0 \%, P<0.0167$ ), lung $\mathrm{V}_{5 \text { Gy }}$ (photon vs proton: $25.2 \%$ vs $4.7 \%, P<0.0167$ ), lung $\mathrm{D}_{\text {mean }}$ (photon vs proton: 27.3 vs $0.88 \mathrm{~Gy}, P<0.0167$ ), heart $\mathrm{V}_{20 \text { Gy }}$ (photon vs proton: $0.7 \%$ vs $0 \%, P<0.0167$ ), heart $\mathrm{V}_{5}$ Gy (photon vs proton: $4.3 \%$ vs $0 \%, P<0.0167$ ), heart $\mathrm{D}_{\text {mean }}$ 


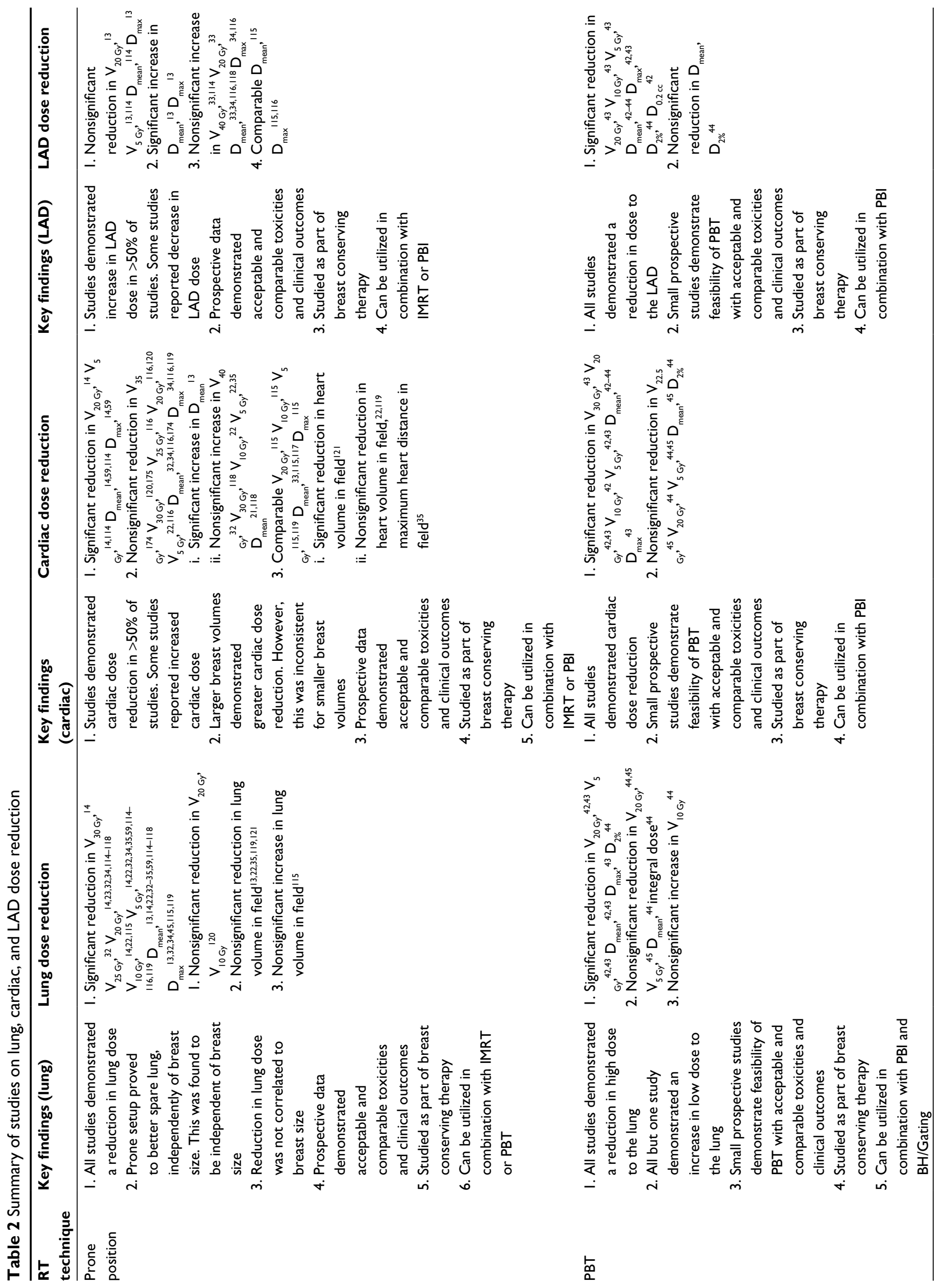




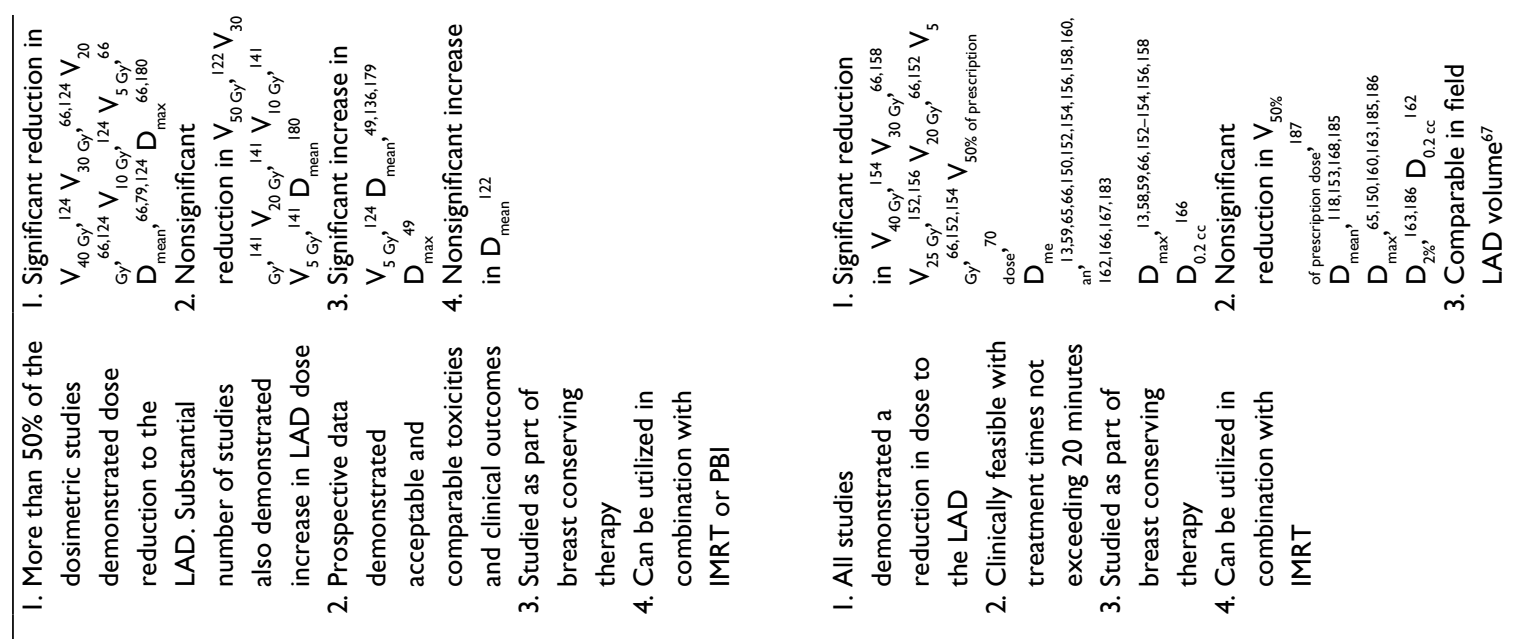

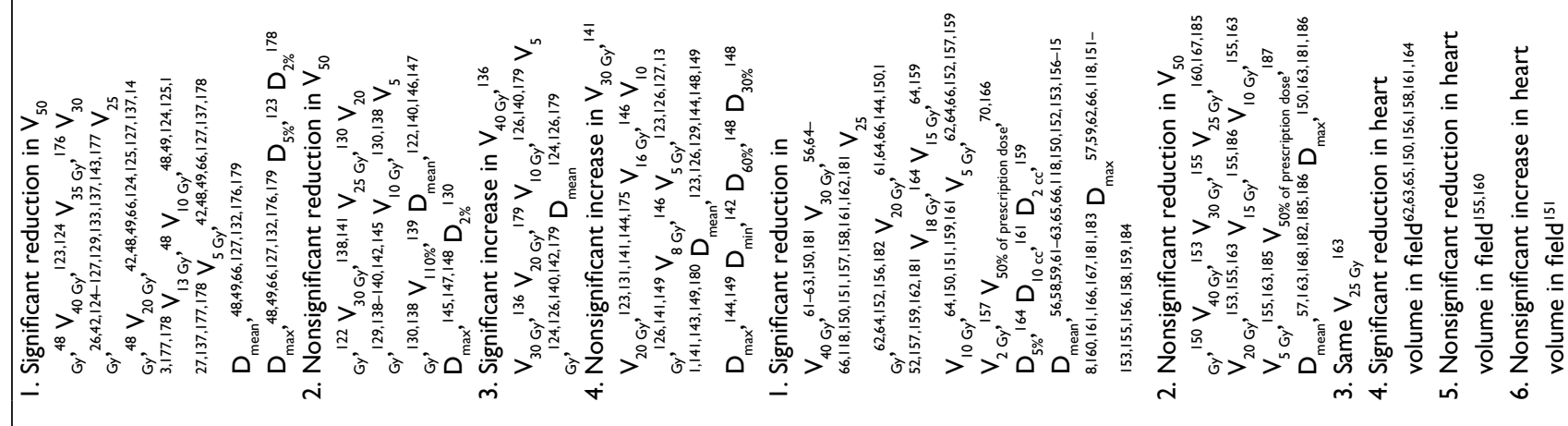

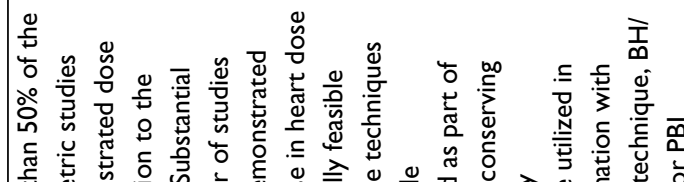

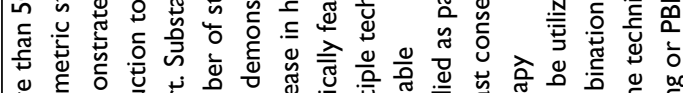

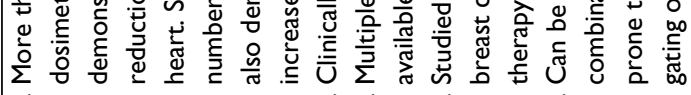

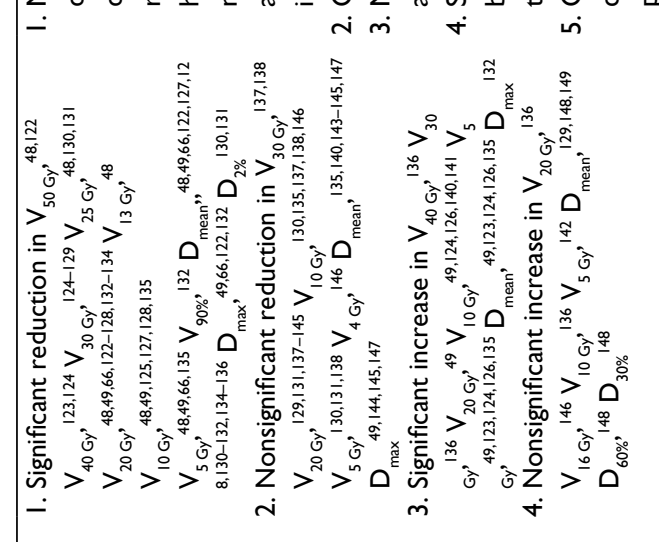

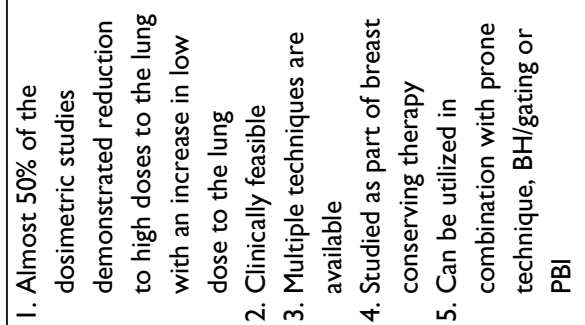

占

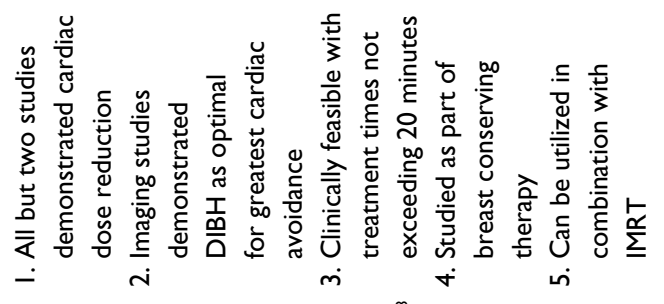

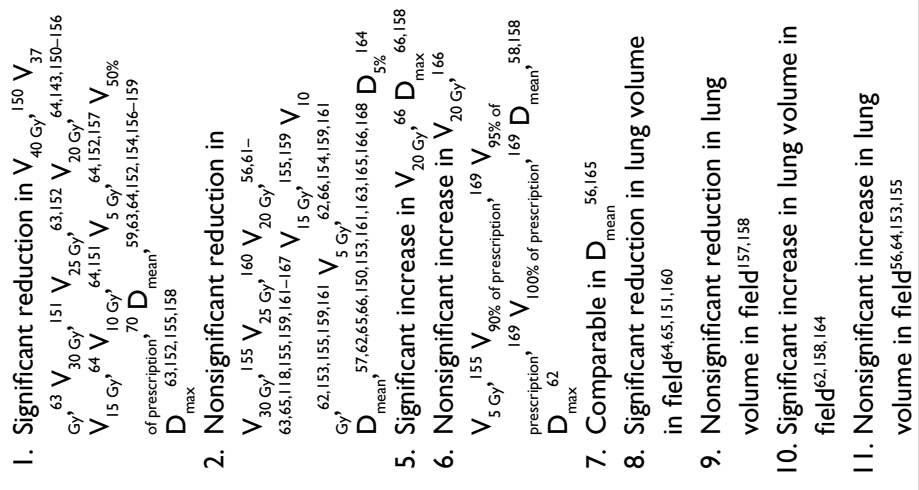

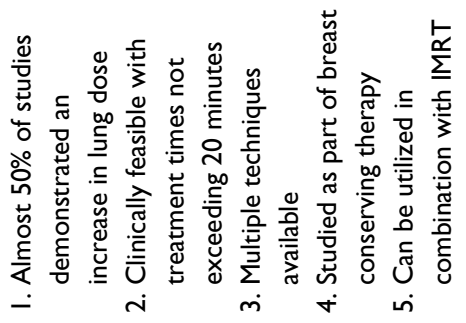

I 


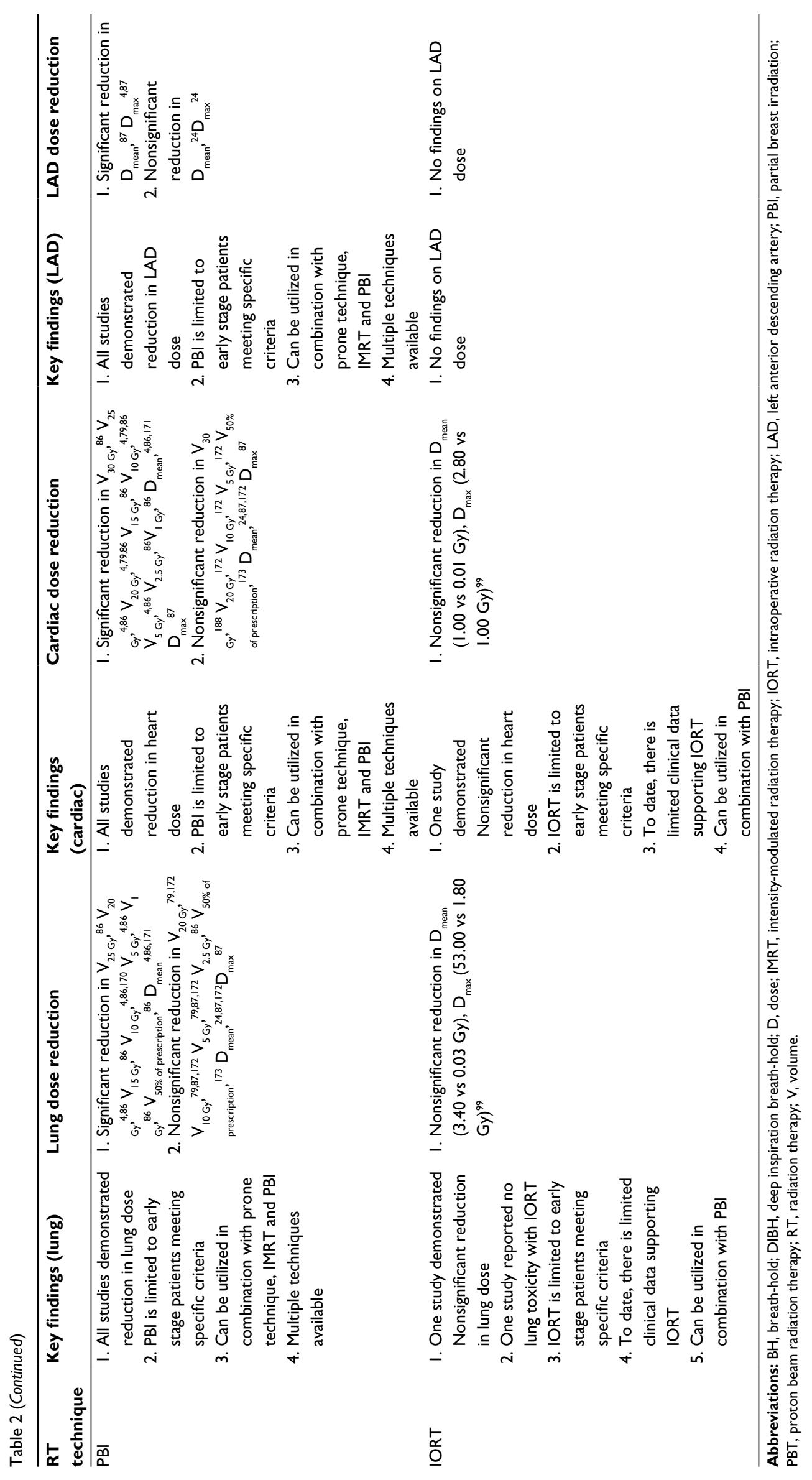


(photon vs proton: 1.6 vs $0.011 \mathrm{~Gy}, P<0.0167)$, LAD D (photon vs proton: 1.1 vs $0 \mathrm{~Gy}$ ), LAD $\mathrm{D}_{\max }$ (photon vs proton: 31.8 vs $0.71 \mathrm{~Gy}, P<0.0167$ ), and LAD D $0.2 \mathrm{cc}$ (photon vs proton: 10 vs $0.052 \mathrm{~Gy}, P<0.0167)$. This could be attributed to the physical properties of PBT.

\section{Concerns regarding PBT}

Although the merits of PBT lie in its potential to reduce radiation-induced morbidities, a prevalent concern underlying the widespread adoption of PBT is its significant cost. Proponents for the adoption of breast PBT argue that two emerging issues may increase the cost-effectiveness for breast PBT. First, as technology rapidly advances and efficiency in delivery improves, costs will become more manageable. Second, the cost of PBT can be further reduced with the adoption of hypofractionated regime.

\section{Current scenario}

The advantageous dose distribution and excellent OAR sparing that can be achieved coupled with growing experience with PBT makes PBT an attractive option. However, data on PBT for breast remains sparse and costs remain significantly high. Given limited data and uncertainty in estimating the cost-benefits, judicious adoption of PBT is recommended.

\section{IMRT}

IMRT is the utility of multileaf collimator (MLC) technology to shape and create non-uniform intensity of radiation beams as it transverse through the patient's body. ${ }^{46,47}$ By varying the speeds at which the MLC leaves travel or the shape of the beam, the radiation beam is effectively shaped to vary the dose distribution to the target volume. ${ }^{47}$

In recent decades, IMRT has emerged as a revolutionary concept that irradiates the tumor more precisely while relatively sparing dose to adjacent OARs. The main advantage of IMRT is that it allows dose painting. ${ }^{46}$

\section{Lung, heart, and LAD exposure with IMRT}

OARs dose reductions with IMRT are contradictory. For example, Schubert et al demonstrated significant reductions in lung $\mathrm{V}_{20 \text { Gy }}$ (three-dimensional conformal radiotherapy [3D CRT] vs IMRT: $14.8 \%$ vs $11.8 \%, P<0.001)$, lung $\mathrm{V}_{5 \text { Gy }}$ (3D CRT vs IMRT: $28.1 \%$ vs $24.1 \%, P<0.001$ ), and lung $\mathrm{D}_{\text {mean }}$ (3D CRT vs IMRT: 8.1 vs $\left.6.6 \mathrm{~Gy}, P<0.001\right) .{ }^{48}$ However Haciislamoglu et al demonstrated instead a significant increase in lung $\mathrm{V}_{20 \mathrm{~Gy}}$ (3D CRT vs IMRT: $12.99 \%$ vs $16.64 \%$, $P=0.005$ ), lung $\mathrm{V}_{5 \text { Gy }}$ (3D CRT vs IMRT: $19.8 \%$ vs $79.92 \%$, $P<0.001)$, and lung $\mathrm{D}_{\text {mean }}$ (3D CRT vs IMRT: 7.66 vs 12.18
Gy; $P<0.001) .{ }^{49}$ Conflicting results have also been demonstrated for both the heart and the LAD.

More than $50 \%$ of the articles demonstrated a reduction in high doses and an increase in low doses to the OARs. This increase in low dose could be attributed to two factors: 1) the number of monitor units increases which results in increase in total body radiation dose and 2) IMRT utilizes more fields resulting in greater volume of normal tissues exposed to low radiation doses. ${ }^{50,51}$ Theoretically, an increase in low dose exposure leads to increased rates of radiation-induced secondary malignancies. ${ }^{49}$ Compared to $3 \mathrm{D}$ CRT, IMRT can potentially increase the incidence of solid secondary cancers due to a combination of changed dose distribution and increase in monitor units. As radiation-induced carcinogenesis is due to the stochastic effect of normal tissue radiation exposure, it is imperative that strategies to decrease OAR dose without compromising adequate dose coverage are implemented.

\section{Concerns regarding IMRT}

Of concern is the conundrum posed by involuntary tumor and patient movement. As in all IMRT cases, the planning target volume (PTV) drawn must encompass all known diseases. This means that all possible movements by both the tumor and the patient should be accounted for. An inappropriate margin will result in underdosing of the tumor and/or overdosing of the surrounding OAR. Hence, extra caution should be taken to limit patient movement with an appropriate reproducible patient immobilization. ${ }^{46}$

Another conundrum is the existence of conflicting data regarding the dosimetric superiority of IMRT over 3D CRT. Compared to prone and breathing techniques, the dosimetric benefits of IMRT proved inconsistent in reducing lung, heart, and LAD doses and its associated NTCPs. Although literature suggests that IMRT is not routinely advantageous, IMRT can prove useful for patients with atypical anatomy such as severe pectus excavatum. ${ }^{52}$

\section{Current scenario}

IMRT represents an often-used technique in a clinical setting with conflicting data with respect to OAR dose reduction. IMRT can also be utilized with breathing techniques, prone technique, and PBI.

\section{$\mathrm{BH}$}

Respiratory maneuvers, primarily utilized for cardiac dose reduction, have been picking up over the past decades. ${ }^{53-55}$ Respiratory maneuvers such as inspiration pulls the heart and diaphragm inferiorly while expanding the thoracic cav- 
ity. ${ }^{53-55}$ This increases the heart to chest wall distance. As radiation-induced heart toxicities correlates to the in-field heart volume within the radiation fields, respiratory maneuvers that reduces in-field heart volume shows promise in reducing radiation dose to the heart while allowing adequate dose to the breast. Later studies affirmed that deep inspiration breath-hold (DIBH) represents the optimum point of heart displacement. ${ }^{56}$ With the development of more sustainable and reproducible methods, multiple studies were conducted comparing free breathing (FB) vs DIBH.

\section{Lung exposure with $\mathrm{BH}$}

Conflicting results regarding lung dose reduction with DIBH exists with multiple studies demonstrating an increase in lung dose with $\mathrm{BH}$. Remouchamps et al demonstrated a significant increase in $\mathrm{V}_{20 \text { Gy }}$ (DIBH vs FB: $20.4 \%$ vs $15.2 \%, P<0.00007$ ) with DIBH. ${ }^{56}$ However, recent studies have also demonstrated comparable or nonsignificant increases in lung doses with DIBH. ${ }^{57,58}$ There are two possible reasons why DIBH results in the increase in lung dose. First, during DIBH, the lungs expand and hence increase in volume. Furthermore, with the displacement of the heart away from the chest wall, this increases the absolute lung volume within the radiation fields. Hence, the significant increase of in-field lung volume correlates to an increase in lung doses. Both Walston et al and Mulliez et al demonstrated an increase in lung volume (DIBH vs FB: $2,059.39 \mathrm{cc}$ vs $1,181.34 \mathrm{cc}, P<0.05$ and DIBH vs FB: $2,090 \mathrm{cc}$ vs $1,235 \mathrm{cc}, P<0.001)$ with $\mathrm{DIBH}$, respectively. ${ }^{57,59}$ Second, the maturation of technology has allowed MLCs to be employed for customized shielding of normal lung tissue. ${ }^{60}$ Hence, although the expansion in lung volume with DIBH is inevitable, the correlated significant increase in lung dose can be mitigated with the use of MLCs.

\section{Cardiac and LAD exposure with $\mathrm{BH}$}

The reduction of in-field heart volume of the heart has allowed for a significant DVH reduction, for the heart and LAD, with DIBH.

Nissen and Appelt demonstrated a $91 \%$ reduction in $\mathrm{V}_{40 \text { Gy }}$ (DIBH vs FB: $3.4 \%$ to $0.3 \%, P<0.0001$ ) and a $48 \%$ reduction in $\mathrm{D}_{\text {mean }}$ (DIBH vs FB: 5.2 vs $2.7 \mathrm{~Gy}, P<0.0001$ ) for left-sided breast plans. ${ }^{61}$ This improvement in cardiac dose reduction was replicated in a prospective trial conducted by EldredgeHindy et al. ${ }^{62}$ Significant reductions in heart DVHs such as $\mathrm{D}_{\text {mean }}$ (DIBH vs FB: 0.9 vs $\left.2.7 \mathrm{~Gy}, P<0.0001\right), \mathrm{D}_{\text {max }}(\mathrm{DIBH}$ vs FB: 27.9 vs $50.4 \mathrm{~Gy}, P<0.0001), \mathrm{V}_{25 \mathrm{~Gy}}$ (DIBH vs FB: $0 \%$ vs $2.7 \%, P<0.0001$ ), and $\mathrm{V}_{5 \text { Gy }}$ (DIBH vs FB: $3 \%$ vs $11.1 \%$, $P<0.0001)$ were established. ${ }^{62}$ These results confirm earlier cardiac imaging findings demonstrating left ventricular dose reduction with DIBH. ${ }^{63-65}$

The LAD descends along the caudal aspect of the heart and is situated in the vicinity of the radiation fields even in $\mathrm{BH}$ plans. Hence with $\mathrm{BH}$, greater significant reductions to the LAD DVHs can be expected. However, greater significant reductions to the LAD DVHs can be expected. Mast et al, utilizing a DIBH device known as active breathing coordinator $(A B C)$ to perform DIBH, demonstrated significant reductions in the LAD DVHs such as $\mathrm{D}_{\text {mean }}\left(\mathrm{ABC}\right.$ vs FB: 9.6 vs $18.6 \mathrm{~Gy}, P<0.01$ ), $\mathrm{D}_{\max }(\mathrm{ABC}$ vs FB: 25.2 vs $35.5 \mathrm{~Gy}, P<0.01$ ), $\mathrm{V}_{20 \mathrm{~Gy}}(\mathrm{ABC}$ vs FB: $17.8 \%$ vs $42.5 \%, P<0.01$ ), and $\mathrm{V}_{5 \text { Gy }}$ (ABC vs FB: $39.4 \%$ vs $62.6 \%$, $P<0.01)$ with ABC. ${ }^{66}$ When used in combination with IMRT, further reduction in dose was achieved, $\mathrm{D}_{\text {mean }}(\mathrm{ABC}$ vs $\mathrm{FB}$ : 6.7 vs $14.9 \mathrm{~Gy}, P<0.01$ ), $\mathrm{D}_{\text {max }}$ (ABC vs FB: 18.8 vs $31.4 \mathrm{~Gy}$, $P<0.01), \mathrm{V}_{20 \text { Gy }}$ (ABC vs FB: $30.3 \%$ vs $54.9 \%, P<0.01$ ), and $\mathrm{V}_{5}$ Gy (ABC vs FB: $9.7 \%$ vs 32.8\%, $P<0.01$ ). Further reduction was demonstrated with IMRT due to a rotation in collimator angle which allowed the MLCs to better shield the heart.

\section{$\mathrm{BH}$ versus respiratory gating}

Two techniques frequently used for breathing cycle management are DIBH and respiratory gating.

DIBH can be device assisted, that is, by using ABC or performed voluntarily. A Phase III randomized trial by Bartlett et al sought to determine whether voluntary DIBH (vDIBH) and $\mathrm{ABC}$ result in a discrepancy in normal tissue sparing, set up reproducibility and feasibility of delivery. ${ }^{67}$ In terms of normal tissue dose, Bartlett et al found no statistical significance in techniques (all $P$ Nonsignificant). Furthermore, positional reproducibility and feasibility of delivery were also comparable. ${ }^{67}$

Respiratory gating tracks the respiratory cycles of the patient with thoraco-abdominal sensors to trigger radiation delivery based on the respiratory phase. ${ }^{68,69}$ Giraud et al evaluated 233 patients and found comparable and consistent reduction in heart DVHs. ${ }^{63}$

Currently, only limited data are available to determine the superiority of one breathing technique over another. However, the wealth of literature with respect to $\mathrm{BH}$ has affirmed its efficacy and feasibility in treatment delivery and dose reduction to OARs.

A reduction in doses to the OARs correlates to reduction in associated radiation-induced OAR toxicities and mortality. Korreman et al evaluated the radiobiological implications of dosimetric benefits offered with breathing techniques and found significant potential. ${ }^{70}$ Corresponding pneumonitis probability dropped from $28.1 \%$ (range: $0.7 \%-95.6 \%$ ) with 
FB to $2.6 \%$ (range: $0.1 \%-40.1 \%$ ) with respiratory gating and to $4.3 \%$ (range: $0.1 \%-59 \%$ ) with DIBH. Likewise, cardiac mortality probability dropped from $4.8 \%$ (range: $0.1 \%-23.4 \%$ ) with FB to $0.5 \%$ (range: $0.1 \%-2.6 \%$ ) with respiratory gating and to $0.1 \%$ (range: $0 \%-3.0 \%$ ) with $\mathrm{DIBH}$.

\section{Current scenario}

$\mathrm{BH}$ is undoubtedly one of the most well-studied RT techniques. It can be offered to all patients except patients unable to sustain $\mathrm{BH}$ or who have poor respiratory function. $\mathrm{BH}$ can also be used in combination with IMRT.

\section{PBI}

PBI is an alternative RT technique that utilizes hypofractionation regimes for selected patients with early stage breast cancer. Patient selection is based on a review of clinical and pathological factors. ${ }^{4}$ As only the lumpectomy cavity and a margin around it is irradiated, patient selection is the foremost factor. This includes assessing presurgical and surgical tumor staging to exclude patients at a greater risk of locoregional recurrence. ${ }^{71}$ Hence, with a reduced irradiated volume, it can be expected that OARs doses decrease.

Increased fraction size results in increased radiobiological equivalent dose to the tumor. However, this is also at the expense of late responding fraction-sensitive OARs, such as the lungs and heart, receiving incidental radiation at an increased dose per fraction too. Hence, a concern regarding a hypofractionation regime associated with $\mathrm{PBI}$ is the potential to increase the risk of lung and heart toxicities due to the low $\alpha / \beta$ of these tissues. The clinical aftermath of receiving higher dose per fraction of incidental radiation to these OARs is as yet unknown. Current data show that toxicities associated with hypofractionation in breast RT have not been correlated with increased OAR-related toxicities. ${ }^{72,73}$

\section{Cardiac and pulmonary exposure with different types of PBI}

APBI is a form of PBI which can be delivered via interstitial devices, applicators, or with external beam. ${ }^{20}$

The case for APBI lies in that a rare $3 \%-4 \%$ of cases report ipsilateral breast recurrences in areas away from the tumor bed. ${ }^{74}$ Based on this evidence, WBEBRT may constitute overtreatment as it incorporates the entire breast (inclusive of the surgical cavity), overlying skin, lower axilla, and portions of the heart, lung, and LAD in the treatment fields. Even with modern WBEBRT, unavoidable OAR toxicities are still introduced where APBI can effectively spare more of these OARs. Thus, the theoretical advantage of APBI is its reduced dose to normal tissues as it can be expected that with a reduced target volume, adjacent OARs such as lungs, heart, and LAD will receive less radiation.

Recent long-term studies have attested the clinical efficacy of APBI with excellent local control, toxicities, and cosmesis that are comparable or reduced compared to WBEBRT. ${ }^{75-77}$

With interstitial APBI, multiple catheters are inserted and loaded around the lumpectomy cavity. ${ }^{75}$ Utilizing high dose rate (HDR) brachytherapy, the target volume receives a high dose away from the chest wall. Applicator-based APBI similarly employs HDR brachytherapy while limiting the dose to the chest wall and adjacent OARs too. ${ }^{78}$ With external beam APBI (EB-APBI), target volume margins are further enlarged to account for respiratory motions and treatment setup uncertainties not typically associated with brachytherapy. Multiple noncoplanar fields are optimally arranged to limit dose to the OARs. ${ }^{79}$

Multi-catheter interstitial brachytherapy has the longest follow-up of any APBI technique to date. Modern image-guided techniques have demonstrated reduced OAR doses. ${ }^{80,81}$ Multiplane interstitial APBI plans were evaluated for 49 patients. The mean heart dose was found to be $21 \%$ of the prescribed dose and a mean $\mathrm{V}_{5}$ of $12.8 \mathrm{cc}$ for leftsided breast cancer patients. ${ }^{81}$ These findings are consistent with Lettmaier's et al study that compared interstitial APBI with standard WBEBRT. ${ }^{82}$ Lettmaier et al demonstrated that interstitial APBI was consistent in reducing both high and low doses to the OARs; 1 ) heart $\mathrm{D}_{0.1 \mathrm{cc}}$ (APBI vs WBEBRT: 12.59 vs $45.60 \mathrm{~Gy}, P<0.01$ ), heart $\mathrm{D}_{50 \mathrm{cc}}$ (APBI vs WBEBRT: 5.60 vs $18.17 \mathrm{~Gy}, P<0.01$ ); 2) lung $\mathrm{D}_{0.1 \mathrm{cc}}$ (APBI vs WBEBRT: 19.61 vs $51.99 \mathrm{~Gy}, P<0.01$ ), lung $\mathrm{D}_{50 \mathrm{cc}}$ (APBI vs WBEBRT: 8.19 vs 43.38 Gy, $P<0.01){ }^{82}$

In recent years, applicator-based brachytherapy has been gaining traction. Stewart et al performed a dosimetric analysis comparing balloon-based APBI to WBEBRT and found significant reduction in OAR doses too: 1) heart $\mathrm{D}_{\max }$ (APBI vs WBEBRT: 16.6 vs $44.1 \mathrm{~Gy}, P<0.05)$, heart $\mathrm{V}_{20 \text { Gy }}$ (APBI vs WBEBRT: $0.1 \%$ vs $3.7 \%, P<0.05$ ); 2 ) lung $\mathrm{D}_{\max }$ (APBI vs WBEBRT: 31.0 vs $51.6 \mathrm{~Gy}, P=0.06$ ), lung $\mathrm{V}_{20 \mathrm{~Gy}}$ (APBI vs WBEBRT: $1.3 \%$ vs $10.0 \%, P<0.05) .{ }^{83}$ With the introduction of multi-lumen applicators, doses can be better sculpted around the target volume to allow further reductions from the OARs. ${ }^{78,84}$

With EB-APBI, the reduction in OAR doses was significantly dependent on the distance from the lumpectomy region. For example, Kron et al found that when lumpectomy regions are $>4 \mathrm{~cm}$ away from the heart, the corresponding $\mathrm{V}_{5 \text { Gy }}$ would be typically $<1 \%{ }^{85}$ 
Multiple studies have affirmed that techniques such as IMRT, BH, PBT, and prone technique, utilized in WBEBRT can be incorporated with APBI to achieve greater OAR dose reduction. Wu et al compared IMRT-APBI and IMRTWBEBRT and found significant reductions in lung and heart DVHs. Lung $\mathrm{D}_{\text {mean }}$ was reduced by a factor of 2 (IMRT-APBI vs IMRT-WBEBRT: 3.17 vs $6.62 \mathrm{~Gy}, P<0.05)$ and lung $\mathrm{V}_{20}$ ${ }_{\text {Gy }}$ was reduced by a factor of 6 (IMRT-APBI vs IMRT-WBEBRT: 1.97 vs $11.77 \mathrm{~Gy}, P<0.05) .{ }^{86}$ Likewise, heart $\mathrm{D}_{\text {mean }}$ was reduced by a factor of 4 (IMRT-APBI vs IMRT-WBEBRT: 0.8 vs $3.17 \mathrm{~Gy}, P<0.05)$ and heart $\mathrm{V}_{20 \text { Gy }}$ was reduced by a factor of 96 (IMRT-APBI vs IMRT-WBEBRT: 0.03 vs $2.88 \mathrm{~Gy}$, $P<0.05)$. Moran et al conducted a Phase $\mathrm{I} / \mathrm{II}$ study evaluating the dosimetric impact of APBI with $\mathrm{BH} .{ }^{87}$ With $\mathrm{BH}$, lung $\mathrm{D}_{\max }$ (FB-APBI vs BH-APBI: 38.1 vs $35.5 \mathrm{~Gy}, P>0.001$ ) and $\mathrm{D}_{\text {mean }}$ (FB-APBI vs BH-APBI: 2.9 vs $1.7 \mathrm{~Gy}, P>0.001$ ) was further reduced. Likewise, heart $\mathrm{D}_{\text {max }}$ (FB-APBI vs BH-APBI: 8.2 vs $4.8 \mathrm{~Gy}, P>0.001$ ) and $\mathrm{D}_{\text {mean }}$ (FB-APBI vs BH-APBI: 0.5 vs $0.4 \mathrm{~Gy}, P>0.001$ ) was further reduced. Galland-Girodet et al conducted a prospective study to compare the impact of photons vs proton on APBI OAR dosimetry. ${ }^{88}$ With proton, lung $\mathrm{D}_{\text {max }}$ (photon-APBI vs proton-APBI: 28.9 vs $20.4 \mathrm{~Gy}$, $P<0.0001$ ) and Dmean (photon-APBI vs proton-APBI: 2.2 vs $0.5 \mathrm{~Gy}, P<0.0001$ ) were further significantly reduced. With proton, heart $\mathrm{D}_{\text {max }}$ (photon-APBI vs proton-APBI: 7.7 vs 3.8 $\mathrm{Gy}, P<0.0001$ ) and $\mathrm{D}_{\text {mean }}$ (photon-APBI vs proton-APBI: 0.9 vs $0.0 \mathrm{~Gy}, P<0.0001$ ) was further significantly reduced. EBAPBI can also be delivered in the prone position. Prospective trials have demonstrated that EB-APBI is compliant to dosimetric requirements. ${ }^{89,90}$ However, Formenti et al found that prone EB-APBI resulted in an increase in cardiac dose in 19 of 30 plans compared to a decrease in cardiac dose in seven of 30 plans. ${ }^{89}$

In essence, EB-APBI allows for excellent lung and heart dose reduction. However, recent interim cosmetic and toxicities results of EB-APBI from the Canadian RAPID trial have demonstrated that current prescribed fractionation regime for EB-APBI approaches the steep aspect of the toxicity curve and cautions against adopting it as standard practice. ${ }^{91}$

\section{Current scenario}

APBI is an effective alternative to WBEBRT in the management of carefully selected patients with early stage breast cancer or ductal carcinoma in situ based on recently published consensus guidelines. ${ }^{77}$ As EB-APBI approaches the steep aspect of toxicity curve, we do not advocate the adoption of EB-APBI as standard practice.

\section{IORT}

IORT represents an alternative to postoperative irradiation as it delivers radiation at the time of surgery as a single fraction in most cases. IORT is increasingly offered as definitive RT following breast conserving surgery. Currently, data on IORT remains far more limited than APBI ${ }^{92-96}$ IORT can be delivered via electrons utilizing lead shielding to reduce dose beyond chest wall..$^{95-98}$ Aziz et al compared the dosimetric gains of utilizing IORT compared to APBI and WBEBRT and demonstrated a reduction of $\mathrm{D}_{\text {mean }}$ from 3.4 to 0.13 and 0.03 Gy with WBEBRT, APBI, and IORT, respectively. ${ }^{99}$ Lung $\mathrm{D}_{\max }$ was likewise reduced from 53.0 to 7.4 and $1.8 \mathrm{~Gy}$ with WBEBRT, APBI, and IORT, respectively. Similar findings were also demonstrated for heart dose where heart $\mathrm{D}_{\text {mean }}$ was reduced from 1.00 to 0.06 and 0.01 Gy with WBEBRT, APBI, and IORT, respectively. Although dosimetric gains achieved with IORT are certainly promising, IORT is not without its controversy.

Two large randomized trials were undertaken to compare the efficacy of IORT in early stage breast cancer with WBEBRT. The targeted intraoperative radiotherapy (TARGIT) trial found that one-fifth of the IORT cohort needed WBEBRT supplementation and was further associated with an inferior local control at 5 years $(3.3 \%$ vs $1.3 \%, P=0.04){ }^{95}$ Similarly, the intraoperative radiotherapy with electrons (ELIOT) trial demonstrated a significantly higher 5-year ipsilateral breast tumor recurrence compared to the WBEBRT $\operatorname{arm}(4.4 \%$ vs $0.4 \%, P=0.0001) .{ }^{96}$ Based on these data, IORT as definitive treatment is discouraged.

\section{Current scenario}

In view of higher rates of local recurrence with IORT and inadequate data to support its safety, efficacy, and widespread adoption compared to WBEBRT or APBI, IORT is discouraged.

\section{Discussion}

Breast-conserving surgery with adjuvant RT is the standard treatment for ESNNBC. A recent meta-analysis found that in women with $\mathrm{pN} 0$ disease, $\mathrm{RT}$ reduced these risks from $31.0 \%$ to $15.6 \%$ (absolute recurrence reduction $15.4 \%, 13.2-17.6$, $2 P<0.00001$ ) and from $20.5 \%$ to $17.2 \%$ (absolute mortality reduction $3.3 \%, 0.8-5.8,2 P=0.005)$, respectively. ${ }^{100}$ With many long-term survivors, treatment-induced toxicities are a major consideration. Concerns regarding the necessity of whole breast irradiation, treatment-associated toxicities, quality of life (QOL) based on these treatments are the subjects of current clinical trials. 
Data from population studies and older literature have shown increase in heart, lung, and LAD morbidity and mortality. ${ }^{7,8,101}$ While pulmonary and cardiac toxicities affect the patients' QOL, it is the cardiac toxicities that have a greater potential to become lethal. Hence, patients with left-sided breast cancer should be offered some form of heart dose sparing technique.

The literature search resulted in six RT techniques that have been consistently utilized and studied: 1) prone positioning, (2) PBT, (3) IMRT, (4) BH, (5) PBI, and (6) IORT (Table 1).

Of these techniques, PBT and PBI have consistently reduced OAR doses. The other techniques have demonstrated dose reduction to OARs in most cases, with some cases reporting an increase in OAR doses (Table 2).

APBI has consistently demonstrated great reductions in both high and low dose for the lungs, heart, and LAD. These reductions are possible as APBI only irradiates the lumpectomy region compared to WBEBRT. ${ }^{20}$ When examining all APBI techniques, EB-APBI demonstrates many advantages over other techniques. ${ }^{102}$ First, EB-APBI is non-invasive. This potentially reduces the risk of invasive complications. Second, EB-APBI allows for widespread adoption as most centers are already performing 3D-CRT for other cancers. Third, adopting EB-APBI may be hassle-free compared to adopting brachytherapy APBI techniques as technical and quality assurance needs of external beam are much simpler. Fourth, treatment outcomes with EB-APBI may be more uniform across centers as the outcome is less operator dependent. Disadvantages of EB-APBI include errors contributed by breathing motions, treatment setup variation, and fractionation regime.

Fractionation regime for EB-APBI remains questionable. Multiple studies demonstrate different fractionation scheme and concerns regarding the steep aspect of the toxicity curve, thus cautions against its widespread adoption. ${ }^{91,103}$

However, the other APBI techniques which fall under the branch of brachytherapy can be safely delivered well within acceptable toxicity standards while achieving comparable OAR dose reduction. The premise of brachytherapy lies in the inverse square law inherent to radioactive sources which allows the delivery of high tumoricidal radiation dose within the tumor bed with substantial sparing of the normal surrounding tissues. ${ }^{104}$ Despite interstitial brachytherapy being a surgical procedure, it presents many advantages too. Reasons to decline standard adjuvant WBEBRT RT include traveling to radiation facilities, daily transport issues, old age, or physical handicap. ${ }^{105,106}$ Brachytherapy APBI may allow such patients to receive standard breast conserving treatment. Brachytherapy APBI, which can be completed over 4-5 days, potentially allows all localized therapy to be completed before the start of systemic therapy. This is crucial for local control as patients will need to undergo 4-6 months of chemotherapy prior to adjuvant breast RT. A disadvantage of brachytherapy APBI is the availability of brachytherapy APBI as a service in the radiation facility which the patient visits.

IORT is technically PBI. However, unlike other APBI techniques, radiation is delivered as a single fraction at the time of lumpectomy. ${ }^{107}$ This makes it an attractive alternative to standard WBEBRT or APBI. IORT is increasingly offered as definitive RT during breast conserving surgery. This is alarming as the pathological and nodal statuses are not reviewed prior to the administration of IORT. Furthermore with limited data supporting its safety and efficacy compared to other RT techniques, IORT is essentially an off-protocol treatment. Beyond clinical data, there exist significant concerns regarding the radiobiology and physics of IORT techniques. With respect to IORT utilizing $50 \mathrm{kv}$ $\mathrm{X}$-ray source, although the surface dose is $20 \mathrm{~Gy}$, the dose is drastically attenuated to $5 \mathrm{~Gy}$, as a single dose, at $1 \mathrm{~cm}$ from the source surface distance. This sharply contrasts against a typical APBI plan that delivers 3.4 Gy to the PTV. Hence, it is unsurprising that randomized trials report higher rates of local recurrence. ${ }^{108}$ Another significant concern is the lack of image guidance. Without it, identification and documentation of the precise location of dose delivery and dose received by OARs remain to be an estimation at best.

While IORT may appear promising, in view of poor clinical outcomes compared to standard WBEBRT, improper adherence to standard radiobiological principles in breast RT and a lack of proper standardized protocols for delivery, clinical data do not support the routine use of IORT.

Where APBI is unavailable or unsuitable, cardiac avoidance techniques with WBEBRT should be explored. A difference in setup position can aid in OAR reduction. ${ }^{29}$ However, from the above data, it is found that OAR dose reduction is inconsistent with the prone position. Also, the prone position requires special immobilization gadgets that may not be available in all centers.

IMRT is consistent in minimizing high dose to the heart, lungs, and LAD. However, the integral dose to these organs, the thorax and the contralateral breast, is often increased with uncertain clinical consequence. Another merit of IMRT is improved breast cosmesis. ${ }^{109}$ Patients who are well endowed benefit most from IMRT. 
The rapid dose fall off beyond the Bragg peak of the proton beam allows for great reductions to OARs beyond the target volume. However, PBT is a significantly expensive treatment and may not be economically attractive despite its consistent reduction in high and low dose to OARs (Table 2).

Patients who are suitable candidates for $\mathrm{BH}$ should be offered if available. BH like PBT consistently reduces high and low doses to heart. However, this is not consistently so for dose to the lungs. All BH delivery methods reduces dose to the heart. The dosimetric advantages with $\mathrm{BH}$ are encouraging. However, there remain two aspects of $\mathrm{BH}$ that needs further research. ${ }^{15}$ First, no clear selection criteria exist to identify which patient group will benefit most from $\mathrm{BH}$ other than the left-sided breast cancer patients. Currently, evidence suggests that parasagittal cardiac contact to the chest wall may be a suitable metric for $\mathrm{BH}$ selection. Second, the success of BH delivery is heavily dependent on patient's compliance and treatment verification. These are additional areas that can be explored further together with coaching strategies.

The impairment of lung function is primarily dependent on the proportion of lung volume receiving a dose beyond its tolerance dose. ${ }^{110}$ Hence, although the lung is one of the most sensitive late responding organ, because of its functional units, only when large volumes of the lungs are irradiated does the lung become a dose-limiting organ.

Lung is inadvertently irradiated during breast RT. Although Lind et al had reassured that RP is an infrequent complication after local WBEBRT $(0.9 \%)$, it is important to bear in mind that the incidence of RP increases with increase in age, concurrent tamoxifen, and prior chemotherapy. ${ }^{111}$ Smoking habits and pre-RT performance status are also important factors in determining the incidence and severity of RP.

Given the anatomical location of heart, potential cardiotoxicity is associated with RT to the left breast. The incidence of ischemic heart disease has been correlated to the volume of heart irradiated and radiation dose received. ${ }^{5,6}$ Although these effects were dominant in early studies based on outdated RT techniques, they serve as a reminder to always minimize cardiac dose where possible. The dosimetric outcomes of clinical studies utilizing modern techniques suggest superior outcomes and a potential decrease in cardiac complications in future long-term follow-up studies. Clinical evidence suggests that radiation to the heart has detrimental consequences despite latencies are estimated to become detectable at only $>15$ years after radiation treatment. ${ }^{112}$
The meta-analysis of the Early Breast Cancer Trialists' Collaborative Group (EBCTCG) found that the gain in locoregional control did not fully translate to an improvement in overall survival. ${ }^{113}$ This was due to life-threatening side effects associated with older RT regimens. The EBCTCG trial reported a significant excess (SE) incidence of contralateral breast cancer (rate ratio 1.18, SE 0.06, $2 P=0.002$ ) and a SE of nonbreast-cancer mortality in irradiated women (rate ratio 1.12, SE $0.04,2 P=0.001$ ) at 15 years after breast RT. The mortality was attributed to cardiovascular disease (rate ratio 1.27, SE $0.07,2 P=0.0001)$ and lung cancer as a secondary malignancy (rate ratio $1.78, \mathrm{SE} 0.22,2 P=0.0004$ ). This suggests that the survival benefit supposedly conferred with adjuvant breast RT was partially negated by the increase in cardiovascular-related death and lung cancer as a secondary malignancy. Therefore, this reinforces that reducing heart and lung irradiation should be a critical aspect in selecting the most appropriate radiation technique for the patient and radiation treatment planning. Patient factors like anatomy, tumor location, its anatomical relation to OAR, and breast contour should be borne in mind when deciding on the most appropriate RT technique.

Current data recommend that where possible and suitable, patients should be first offered PBI. The next best option for OAR dose reduction would be $\mathrm{BH}$.

Long-term studies are needed to evaluate the effect of RT on the heart, LAD, and lungs with modern RT techniques in both the acute and late settings. This could also be particularly helpful in advising patients on lifestyle modification in cases of increased radiation-induced toxicity risks.

\section{Conclusion}

As RT techniques evolve, the focus on survival, control, recurrence, and tissue toxicities remains. Treatment options have to take into consideration patient's schedule, QOL, and the financial impact of different techniques.

Currently, in terms of whole breast irradiation, dosimetric data suggest that $\mathrm{BH}$ techniques allow for consistent cardiac dose reduction at the expense of slight increase in lung doses. This is in contrast to techniques such as the prone position and IMRT. Although PBT achieves consistent OAR dose reduction too, the sheer significantly higher cost makes it unaffordable for most patients. In terms of PBI, APBI has comparable survival, control, and recurrence outcomes with even better cosmesis. IORT is cautioned against in view of its high failure rate and limited data. Among the various radiotherapy modalities, current evidence suggests that PBI multicatheter offers the best heart and lung dosimetry. 


\section{Disclosure}

The authors report no conflicts of interest in this work.

\section{References}

1. Cianfrocca M, Goldstein LJ. Prognostic and predictive factors in early-stage breast cancer. Oncologist. 2004;9(6):606-616.

2. Guarneri V, Conte PF. The curability of breast cancer and the treatment of advanced disease. Eur J Nucl Med Mol Imaging. 2004;31(Suppl 1): S149-S161.

3. Kanapuru B, Ershler WB, Hesdorffer C, Jemal A, Yates JW. Longterm survival of older breast cancer patients: population-based estimates over three decades. Breast Cancer Res Treat. 2012;134(2): 853-857.

4. Chan TY, Tan PW, Tan CW, Tang JI. Assessing radiation exposure of the left anterior descending artery, heart and lung in patients with left breast cancer: a dosimetric comparison between multicatheter accelerated partial breast irradiation and whole breast external beam radiotherapy. Radiother Oncol. 2015;117(3):459-466.

5. Darby SC, Mcgale P, Taylor CW, Peto R. Long-term mortality from heart disease and lung cancer after radiotherapy for early breast cancer: prospective cohort study of about 300000 women in US SEER cancer registries. Lancet Oncol. 2005;6(8):557-565.

6. Darby SC, Ewertz M, McGale P, et al. Risk of ischemic heart disease in women after radiotherapy for breast cancer. $N$ Engl J Med Overseas Ed. 2013;368(11):987-998.

7. Nilsson G, Holmberg L, Garmo H, et al. Distribution of coronary artery stenosis after radiation for breast cancer. $J$ Clin Oncol. 2012;30(4):380-386.

8. Taylor C, Darby SC. Ischemic heart disease and breast cancer radiotherapy. JAMA Intern Med. 2014;174(1):160-161.

9. Darby SC, Cutter DJ, Boerma M, et al. Radiation-related heart disease: current knowledge and future prospects. Int J Radiat Oncol Biol Phys. 2010;76(3):656-665.

10. Grantzau T, Overgaard J. Risk of second non-breast cancer after radiotherapy for breast cancer: a systematic review and meta-analysis of 762,468 patients. Radiotherapy and Oncology. 2015;114(1): $56-65$.

11. Agrawal S. Clinical relevance of radiation pneumonitis in breast cancers. South Asian J Cancer. 2013;2(1):19-20.

12. Beck RE, Kim L, Yue NJ, Haffty BG, Khan AJ, Goyal S. Treatment techniques to reduce cardiac irradiation for breast cancer patients treated with breast-conserving surgery and radiation therapy: a review. Front Oncol. 2014;4:327.

13. Bartlett FR, Colgan RM, Donovan EM, et al. The UK HeartSpare Study (Stage IB): randomised comparison of a voluntary breath-hold technique and prone radiotherapy after breast conserving surgery. Radiother Oncol. 2015;114(1):66-72.

14. Kim H, Kim J. Evaluation of the anatomical parameters for normal tissue sparing in the prone position radiotherapy with small sized left breasts. Oncotarget. 2016;7(44):72211-72218.

15. Latty D, Stuart KE, Wang W, Ahern V. Review of deep inspiration breath-hold techniques for the treatment of breast cancer. J Med Radiat Sci. 2015;62(1):74-81.

16. Yue NJ, Goyal S, Park JH, et al. Optimization of heart block in the left-sided whole breast radiation treatments. Front Oncol. 2014;4:342.

17. Cuaron JJ, Macdonald SM, Cahlon O. Novel applications of proton therapy in breast carcinoma. Chin Clin Oncol. 2016;5:52.

18. Jeulink M, Dahele M, Meijnen P, Slotman BJ, Verbakel WF. Is there a preferred IMRT technique for left-breast irradiation? J Appl Clin Med Phys. 2015;16(3):5266.

19. Holmes DR. Intraoperative radiotherapy of the breast for early-stage breast cancer: ready for primetime. Breast J Cancer (Dove Med Press). 2015;21(2):181-184.
20. Njeh CF, Saunders MW, Langton CM. Accelerated Partial Breast Irradiation (APBI): a review of available techniques. Radiat Oncol. 2010;5(1):90.

21. Huppert N, Jozsef G, Dewyngaert K, Formenti SC. The role of a prone setup in breast radiation therapy. Front Oncol. 2011;1:31.

22. Lymberis SC, deWyngaert JK, Parhar P, et al. Prospective assessment of optimal individual position (prone versus supine) for breast radiotherapy: volumetric and dosimetric correlations in 100 patients. Int $J$ Radiat Oncol Biol Phys. 2012;84(4):902-909.

23. Varga Z, Hideghéty K, Mező T, Nikolényi A, Thurzó L, Kahán Z. Individual positioning: a comparative study of adjuvant breast radiotherapy in the prone versus supine position. Int J Radiat Oncol Biol Phys. 2009;75(1):94-100.

24. Kirby AM, Evans PM, Donovan EM, Convery HM, Haviland JS, Yarnold JR. Prone versus supine positioning for whole and partial-breast radiotherapy: a comparison of non-target tissue dosimetry. Radiother Oncol. 2010;96(2):178-184.

25. Veldeman L, Speleers B, Bakker M, et al. Preliminary results on setup precision of prone-lateral patient positioning for whole breast irradiation. Int J Radiat Oncol Biol Phys. 2010;78(1):111-118.

26. Veldeman L, De Gersem W, Speleers B, et al. Alternated prone and supine whole-breast irradiation using IMRT: setup precision, respiratory movement and treatment time. Int J Radiat Oncol Biol Phys. 2012;82(5):2055-2064.

27. Chen JL, Cheng JC, Kuo SH, Chan HM, Huang YS, Chen YH. Prone breast forward intensity-modulated radiotherapy for Asian women with early left breast cancer: factors for cardiac sparing and clinical outcomes. J Radiat Res. 2013;54(5):899-908.

28. Prochazka M, Hall P, Gagliardi G, et al. Ionizing radiation and tobacco use increases the risk of a subsequent lung carcinoma in women with breast cancer: case-only design. J Clin Oncol. 2005;23(30): 7467-7474.

29. Chino JP, Marks LB. Prone positioning causes the heart to be displaced anteriorly within the thorax: implications for breast cancer treatment Int J Radiat Oncol Biol Phys. 2008;70(3):916-920.

30. Formenti S, Lymberis S, Parhar P, et al. Results of NYU 05-181: a prospective trial to determine optimal position (prone versus supine) for breast radiotherapy. Int J Radiat Oncol Biol Phys. 2009;75(3):S203-S204.

31. Formenti SC, DeWyngaert JK, Jozsef G, Goldberg JD. Prone vs supine positioning for breast cancer radiotherapy. JAMA. 2012;308(9): 861-863.

32. Mulliez T, Speleers B, Madani I, de Gersem W, Veldeman L, de Neve W. Whole breast radiotherapy in prone and supine position: is there a place for multi-beam IMRT? Radiat Oncol. 2013;8:151

33. Würschmidt F, Stoltenberg S, Kretschmer M, Petersen C. Incidental dose to coronary arteries is higher in prone than in supine whole breast irradiation. Strahlenther Onkol. 2014;190(6):563-568.

34. Cammarota F, Giugliano F, Iadanza L, et al. Hypofractionated breast cancer radiotherapy. Helical tomotherapy in supine position or classic 3D conformal radiotherapy in prone position: which is better? Anticancer Res. 2014;34:1233-1238.

35. Ramella S, Trodella L, Ippolito E, et al. Whole-breast irradiation: a subgroup analysis of criteria to stratify for prone position treatment. Med Dosim. 2012;37(2):186-191.

36. Mahe MA, Classe JM, Dravet F, Cussac A, Cuilliere JC. Preliminary results for prone-position breast irradiation. Int J Radiat Oncol Biol Phys. 2002;52(1):156-160.

37. Jozsef G, DeWyngaert JK, Becker SJ, Lymberis S, Formenti SC. Prospective study of cone-beam computed tomography image-guided radiotherapy for prone accelerated partial breast irradiation. Int $J$ Radiat Oncol Biol Phys. 2011;81(2):568-574.

38. De Puysseleyr A, Mulliez T, Gulyban A, et al. Improved cone-beam computed tomography in supine and prone breast radiotherapy Strahlenther Onkol. 2013;189(11):945-950. 
39. Bergom C, Prior P, Kainz K, et al. A phase I/II study piloting accelerated partial breast irradiation using CT-guided intensity modulated radiation therapy in the prone position. Radiother Oncol. 2013;108(2):215-219.

40. Formenti SC, Gidea-Addeo D, Goldberg JD, et al. Phase I-II trial of prone accelerated intensity modulated radiation therapy to the breast to optimally spare normal tissue. J Clin Oncol. 2007;25(16):2236-2242.

41. Stegman LD, Beal KP, Hunt MA, Fornier MN, McCormick B. Longterm clinical outcomes of whole-breast irradiation delivered in the prone position. Int J Radiat Oncol Biol Phys. 2007;68(1):73-81.

42. Lin LL, Vennarini S, Dimofte A, et al. Proton beam versus photon beam dose to the heart and left anterior descending artery for left-sided breast cancer. Acta Oncol. 2015;54(7):1032-1039.

43. Mast ME, Vredeveld EJ, Credoe HM, et al. Whole breast proton irradiation for maximal reduction of heart dose in breast cancer patients. Breast Cancer Res Treat. 2014;148(1):33-39.

44. Flejmer AM, Edvardsson A, Dohlmar F, et al. Respiratory gating for proton beam scanning versus photon 3D-CRT for breast cancer radiotherapy. Acta Oncol. 2016;55(5):577-583.

45. Ares C, Khan S, Macartain AM, et al. Postoperative proton radiotherapy for localized and locoregional breast cancer: potential for clinically relevant improvements? Int J Radiat Oncol Biol Phys. 2010;76(3):685-697.

46. Taylor A, Powell M. Intensity-modulated radiotherapy - what is it? Cancer Imaging. 2004;4(2):68-73.

47. Chan T, Tan PW, Tang J. Intensity-modulated radiation therapy for early-stage breast cancer: is it ready for prime time? Breast Cancer (Dove Med Press). 2017;9:177-183.

48. Schubert LK, Gondi V, Sengbusch E, et al. Dosimetric comparison of left-sided whole breast irradiation with 3DCRT, forward-planned IMRT, inverse-planned IMRT, helical tomotherapy, and topotherapy. Radiother Oncol. 2011;100(2):241-246.

49. Haciislamoglu E, Colak F, Canyilmaz E, et al. The choice of multibeam IMRT for whole breast radiotherapy in early-stage right breast cancer. Springerplus. 2016;5(1):688.

50. Hall EJ, Wuu C-S. Radiation-induced second cancers: the impact of 3D-CRT and IMRT. Int J Radiat Oncol Biol Phys. 2003;56(1):83-88.

51. Kry SF, Salehpour M, Followill DS, et al. The calculated risk of fatal secondary malignancies from intensity-modulated radiation therapy. Int J Radiat Oncol Biol Phys. 2005;62(4):1195-1203.

52. Teh BS, Lu HH, Sobremonte S, et al. The potential use of intensity modulated radiotherapy (IMRT) in women with pectus excavatum desiring breast-conserving therapy. Breast J. 2001;7(4):233-239.

53. Chen MH, Chuang ML, Bornstein BA, Gelman R, Harris JR, Manning WJ. Impact of respiratory maneuvers on cardiac volume within left-breast radiation portals. Circulation. 1997;96(10):3269-3272.

54. Lu H-M, Cash E, Chen MH, et al. Reduction of cardiac volume in left-breast treatment fields by respiratory maneuvers: a CT study. Int J Radiat Oncol Biol Phys. 2000;47(4):895-904.

55. Sixel KE, Aznar MC, Ung YC. Deep inspiration breath hold to reduce irradiated heart volume in breast cancer patients. Int J Radiat Oncol Biol Phys. 2001;49(1):199-204.

56. Remouchamps VM, Vicini FA, Sharpe MB, Kestin LL, Martinez AA, Wong JW. Significant reductions in heart and lung doses using deep inspiration breath hold with active breathing control and intensitymodulated radiation therapy for patients treated with locoregional breast irradiation. Int J Radiat Oncol Biol Phys. 2003;55(2):392-406.

57. Walston S, Quick AM, Kuhn K, Rong Y. Dosimetric considerations in respiratory-gated deep inspiration breath-hold for left breast irradiation. Technol Cancer Res Treat. 2017;16(1):22-32.

58. Bartlett FR, Donovan EM, Mcnair HA, et al. The UK HeartSpare Study (Stage II): multicentre evaluation of a voluntary breath-hold technique in patients receiving breast radiotherapy. Clin Oncol ( $R$ Coll Radiol). 2017;29(3):e51-e56.

59. Mulliez T, Veldeman L, Speleers B, et al. Heart dose reduction by prone deep inspiration breath hold in left-sided breast irradiation. Radiother Oncol. 2015;114(1):79-84.
60. Lee $\mathrm{KC}$, Lee $\mathrm{SH}$, Lee $\mathrm{SH}$, et al. Usefulness of simple shielding technique using multileaf collimator in breast radiation therapy. $J$ Radiat Prot Res. 2014;39(4):168-175.

61. Nissen HD, Appelt AL. Improved heart, lung and target dose with deep inspiration breath hold in a large clinical series of breast cancer patients. Radiother Oncol. 2013;106(1):28-32.

62. Eldredge-Hindy H, Lockamy V, Crawford A, et al. Active breathing coordinator reduces radiation dose to the heart and preserves local control in patients with left breast cancer: report of a prospective trial. Pract Radiat Oncol. 2015;5(1):4-10.

63. Giraud P, Djadi-Prat J, Morelle M, et al. Contribution of respiratory gating techniques for optimization of breast cancer radiotherapy. Cancer Invest. 2012;30(4):323-330.

64. Swanson T, Grills IS, Ye H, et al. Six-year experience routinely using moderate deep inspiration breath-hold for the reduction of cardiac dose in left-sided breast irradiation for patients with early-stage or locally advanced breast cancer. Am J Clin Oncol. 2013;36(1):24-30.

65. Hayden AJ, Rains M, Tiver K. Deep inspiration breath hold technique reduces heart dose from radiotherapy for left-sided breast cancer. $J$ Med Imaging Radiat Oncol. 2012;56(4):464-472.

66. Mast ME, van Kempen-Harteveld L, Heijenbrok MW, et al. Leftsided breast cancer radiotherapy with and without breath-hold: Does IMRT reduce the cardiac dose even further? Radiother Oncol. 2013;108(2):248-253

67. Bartlett FR, Colgan RM, Carr K, et al. The UK HeartSpare Study: randomised evaluation of voluntary deep-inspiratory breath-hold in women undergoing breast radiotherapy. Radiother Oncol. 2013;108(2):242-247.

68. Giraud P, Houle A. Respiratory gating for radiotherapy: main technical aspects and clinical benefits. ISRN Pulmonol. 2013;2013(1):1-13.

69. Hjelstuen MHB, Mjaaland I, Vikström J, Dybvik KI. Radiation during deep inspiration allows loco-regional treatment of left breast and axillary-, supraclavicular- and internal mammary lymph nodes without compromising target coverage or dose restrictions to organs at risk. Acta Oncol. 2012;51(3):333-344.

70. Korreman SS, Pedersen AN, Nøttrup TJ, Specht L, Nyström H. Breathing adapted radiotherapy for breast cancer: comparison of free breathing gating with the breath-hold technique. Radiother Oncol. 2005;76(3):311-318.

71. Stewart AJ, Khan AJ, Devlin PM. Partial breast irradiation: a review of techniques and indications. Br J Radiol. 2010;83(989):369-378.

72. Badiyan SN, Shah C, Arthur D, et al. Hypofractionated regional nodal irradiation for breast cancer: examining the data and potential for future studies. Radiother Oncol. 2014;110(1):39-44.

73. Shaitelman SF, Khan AJ, Woodward WA, et al. Shortened radiation therapy schedules for early-stage breast cancer: a review of hypofractionated whole-breast irradiation and accelerated partial breast irradiation. Breast J. 2014;20(2):131-146.

74. Sanders ME, Scroggins T, Ampil FL, Li BD. Accelerated partial breast irradiation in early-stage breast cancer. J Clin Oncol. 2007;25(8):996-1002.

75. Polgár C, Fodor J, Major T, Sulyok Z, Kásler M. Breast-conserving therapy with partial or whole breast irradiation: ten-year results of the Budapest randomized trial. Radiother Oncol. 2013;108(2): 197-202.

76. Shah C, Antonucci JV, Wilkinson JB, et al. Twelve-year clinical outcomes and patterns of failure with accelerated partial breast irradiation versus whole-breast irradiation: results of a matched-pair analysis. Radiother Oncol. 2011;100(2):210-214.

77. Shah C, Badiyan S, Ben Wilkinson J, et al. Treatment efficacy with accelerated partial breast irradiation (APBI): final analysis of the American Society of Breast Surgeons MammoSite ${ }^{\circledR}$ Breast Brachytherapy Registry Trial. Ann Surg Oncol. 2013;20(10):3279-3285.

78. Shah C, Ghilezan M, Arthur D, et al. Initial clinical experience with multilumen brachytherapy catheters for accelerated partial breast irradiation. Brachytherapy. 2012;11(5):369-373. 
79. Vicini F, Remouchamps V, Wallace M, et al. Ongoing clinical experience utilizing 3D conformal external beam radiotherapy to deliver partial breast irradiation in patients with early stage breast cancer treated with breast conserving therapy. Int J Radiat Oncol Biol Phys 2003;57(5):1247-1253.

80. Major T, Fröhlich G, Lövey K, Fodor J, Polgár C. Dosimetric experience with accelerated partial breast irradiation using image-guided interstitial brachytherapy. Radiother Oncol. 2009;90(1):48-55.

81. Major T, Polgár C, Lövey K, Fröhlich G. Dosimetric characteristics of accelerated partial breast irradiation with CT image-based multicatheter interstitial brachytherapy: a single institution's experience. Brachytherapy. 2011;10(5):421-426.

82. Lettmaier S, Kreppner S, Lotter M, et al. Radiation exposure of the heart, lung and skin by radiation therapy for breast cancer: dosimetric comparison between partial breast irradiation using multicatheter brachytherapy and whole breast teletherapy. Radiother Oncol. 2011;100(2):189-194.

83. Stewart AJ, O'Farrell DA, Cormack RA, et al. Dose volume histogram analysis of normal structures associated with accelerated partial breas irradiation delivered by high dose rate brachytherapy and comparison with whole breast external beam radiotherapy fields. Radiat Oncol. 2008;3:39.

84. Cuttino LW, Todor D, Gilbert L, Arthur DW. A comparison of skin and chest wall dose delivered with multicatheter, Contura ${ }^{\text {TM }}$ Multilumen Balloon, and MammoSite ${ }^{\circledR}$ breast brachytherapy. Brachytherapy. 2009;8(2):118

85. Kron T, Willis D, Link E, et al. Can we predict plan quality for external beam partial breast irradiation: results of a multicenter feasibility study (Trans Tasman Radiation Oncology Group Study 06.02). Int J Radiat Oncol Biol Phys. 2013;87(4):817-824.

86. Wu S, He Z, Guo J, Li F, Lin Q, Guan X. Dosimetric comparison of normal structures associated with accelerated partial breast irradiation and whole breast irradiation delivered by intensity modulated radiotherapy for early breast cancer after breast conserving surgery Clin Transl Oncol. 2014;16(1):69-76.

87. Moran JM, Ben-David MA, Marsh RB, et al. Accelerated partial breast irradiation: what is dosimetric effect of advanced technology approaches? Int J Radiat Oncol Biol Phys. 2009;75(1):294-301.

88. Galland-Girodet S, Pashtan I, MacDonald SM, et al. Long-term cosmetic outcomes and toxicities of proton beam therapy compared with photon-based 3-dimensional conformal accelerated partial-breast irradiation: a phase 1 trial. Int J Radiat Oncol Biol Phys. 2014;90(3): 493-500.

89. Formenti SC, Truong MT, Goldberg JD, et al. Prone accelerated partial breast irradiation after breast-conserving surgery: preliminary clinical results and dose-volume histogram analysis. Int J Radiat Oncol Biol Phys. 2004;60(2):493-504

90. Wen B, Hsu H, Formenti-Ujlaki GF, et al. Prone accelerated partial breast irradiation after breast-conserving surgery: compliance to the dosimetry requirements of RTOG-0413. Int J Radiat Oncol Biol Phys. 2012;84(4):910-916.

91. Olivotto IA, Whelan TJ, Parpia S, et al. Interim cosmetic and toxicity results from RAPID: a randomized trial of accelerated partial breast irradiation using three-dimensional conformal external beam radiation therapy. J Clin Oncol. 2013;31(32):4038-4045.

92. Esposito E, Douek M. Experience with intraoperative radiotherapy for breast cancer: the Geneva University Hospital's experience. Chin J Cancer Res. 2016;28(4):463-466.

93. Showalter SL, Petroni G, Trifiletti DM, et al. A novel form of breast intraoperative radiation therapy with CT-guided high-dose-rate brachytherapy: results of a prospective phase 1 clinical trial. Int $J$ Radiat Oncol Biol Phys. 2016;96(1):46-54.

94. Stish BJ, Pafundi DH, Hieken TJ, et al. Feasibility and full-course dosimetry of an intraoperatively placed multichannel brachytherapy catheter for accelerated partial breast irradiation. Brachytherapy. 2016;15(6):796-803.
95. Vaidya JS, Wenz F, Bulsara M, et al. Risk-adapted targeted intraoperative radiotherapy versus whole-breast radiotherapy for breast cancer: 5-year results for local control and overall survival from the TARGIT-A randomised trial. Lancet. 2014;383(9917):603-613.

96. Veronesi U, Orecchia R, Maisonneuve P, et al. Intraoperative radiotherapy versus external radiotherapy for early breast cancer (ELIOT): a randomised controlled equivalence trial. Lancet Oncol. 2013;14(13):1269-1277.

97. Mobetron - Electron Beam Intraoperative Radiation Therapy - IntraOp [homepage on the Internet]. IntraOp; 2018. Available from: https:// intraop.com/mobetron/. Accessed December 9, 2017.

98. INTRABEAM - Breast Cancer - Oncology - Medical Technology ZEISS United States. Zeiss.com; 2018. Available from: https:/www. zeiss.com/meditec/int/products/intraoperative-radiotherapy-iort/ intrabeam-system.html. Accessed December 9, 2017.

99. Aziz M, Schneider F, Clausen S, et al. Can the risk of secondary cancer induction after breast conserving therapy be reduced using intraoperative radiotherapy (IORT) with low-energy x-rays? Radiat Oncol. 2011;6:174.

100. Early Breast Cancer Trialists' Collaborative Group (EBCTCG). Effect of radiotherapy after breast-conserving surgery on 10-year recurrence and 15-year breast cancer death: meta-analysis of individual patient data for 10801 women in 17 randomised trials. Lancet. 2011;378(9804):1707-1716.

101. Gokula K, Earnest A, Wong L. Meta-analysis of incidence of early lung toxicity in 3-dimensional conformal irradiation of breast carcinomas. Radiat Oncol. 2013;8:268.

102. Formenti SC. External-beam partial-breast irradiation. Semin Radiat Oncol. 2005;15(2):92-99.

103. Rosenstein BS, Lymberis SC, Formenti SC. Biologic comparison of partial breast irradiation protocols. Int J Radiat Oncol Biol Phys. 2004;60(5):1393-1404.

104. James K, Gielty K, Nica L. Breast radiotherapy: an overview of available radiation treatment options and treatment induced sequelae. Can J Med Radiat Technol. 2005;36(4):37-43.

105. Lam J, Cook T, Foster S, Poon R, Milross C, Sundaresan P. Examining determinants of radiotherapy access: do cost and radiotherapy inconvenience affect uptake of breast-conserving treatment for early breast cancer? Clin Oncol (R Coll Radiol). 2015;27(8):465-471.

106. Sauerzapf VA, Jones AP, Haynes R, Crawford SM, Forman D. Travel time to radiotherapy and uptake of breast-conserving surgery for early stage cancer in Northern England. Health Place. 2008;14(3):424- 433.

107. Leonardi MC, Maisonneuve P, Mastropasqua MG, et al. Accelerated partial breast irradiation with intraoperative electrons: using GECESTRO recommendations as guidance for patient selection. Radiother Oncol. 2013;106(1):21-27.

108. Khan AJ, Arthur DW, Vicini FA. On the road to intraoperative radiotherapy: more 'proceed with caution' signs. Oncology (Williston Park). 2013;27(2):113-114,122.

109. Barnett GC, Wilkinson J, Moody AM, et al. A randomised controlled trial of forward-planned radiotherapy (IMRT) for early breast cancer: baseline characteristics and dosimetry results. Radiother Oncol. 2009;92(1):34-41.

110. Fragkandrea I, Kouloulias V, Mavridis P, et al. Radiation induced pneumonitis following whole breast radiotherapy treatment in early breast cancer patients treated with breast conserving surgery: a single institution study. Hippokratia. 2013;17(3):233-238.

111. Lind PA, Marks LB, Hardenbergh PH, et al. Technical factors associated with radiation pneumonitis after local \pm regional radiation therapy for breast cancer. Int J Radiat Oncol Biol Phys. 2002;52(1):137-143.

112. Poortmans P. Optimal approach in early breast cancer: radiation therapy. EJC Suppl. 2013;11(2):27-36.

113. Clarke M, Collins R, Darby S, et al. Effects of radiotherapy and of differences in the extent of surgery for early breast cancer on local recurrence and 15-year survival: an overview of the randomised trials. Lancet. 2005;366(9503):2087-2106 
114. Chen JL, Cheng JC, Kuo SH, Chan HM, Huang YS, Chen YH. Prone breast forward intensity-modulated radiotherapy for Asian women with early left breast cancer: factors for cardiac sparing and clinical outcomes. J Radiat Res. 2013;54(5):899-908.

115. Krengli M, Masini L, Caltavuturo T, et al. Prone versus supine position for adjuvant breast radiotherapy: a prospective study in patients with pendulous breasts. Radiat Oncol. 2013;8:232.

116. Mulliez T, Veldeman L, van Greveling A, et al. Hypofractionated whole breast irradiation for patients with large breasts: a randomized trial comparing prone and supine positions. Radiother Oncol. 2013;108(2):203-208.

117. Takahashi K, Morota M, Kagami Y, et al. Prospective study of postoperative whole breast radiotherapy for Japanese large-breasted women: a clinical and dosimetric comparisons between supine and prone positions and a dose measurement using a breast phantom. BMC Cancer. 2016;16(1):757.

118. Verhoeven K, Sweldens C, Petillion S, et al. Breathing adapted radiation therapy in comparison with prone position to reduce the doses to the heart, left anterior descending coronary artery, and contralateral breast in whole breast radiation therapy. Pract Radiat Oncol. 2014;4(2):123-129.

119. Hardee ME, Raza S, Becker SJ, et al. Prone hypofractionated wholebreast radiotherapy without a boost to the tumor bed: comparable toxicity of IMRT versus a 3D conformal technique. Int J Radiat Oncol Biol Phys. 2012;82(3):e415-e423.

120. Griem KL, Fetherston P, Kuznetsova M, Foster GS, Shott S, Chu J. Three-dimensional photon dosimetry: a comparison of treatment of the intact breast in the supine and prone position. Int J Radiat Oncol Biol Phys. 2003;57(3):891-899.

121. Osa E, Keith Dewyngaert K, Roses D, et al. Five-year results of adjuvant radiotherapy. Int J Radiat Oncol Biol Phys. 2014;89(4):899-906.

122. Sas-Korczyńska B, Śladowska A, Rozwadowska-Bogusz B, et al. Comparison between intensity modulated radiotherapy (IMRT) and 3D tangential beams technique used in patients with early-stage breast cancer who received breast-conserving therapy. Rep Pract Oncol Radiother. 2010;15(4):79-86.

123. Badakhshi H, Kaul D, Nadobny J, Wille B, Sehouli J, Budach V. Image-guided volumetric modulated arc therapy for breast cancer: a feasibility study and plan comparison with three-dimensional conformal and intensity-modulated radiotherapy. $\mathrm{Br} J$ Radiol. 2013;86(1032):20130515.

124. Jin GH, Chen LX, Deng XW, Liu XW, Huang Y, Huang XB. A comparative dosimetric study for treating left-sided breast cancer for small breast size using five different radiotherapy techniques: conventional tangential field, filed-in-filed, Tangential-IMRT, Multi-beam IMRT and VMAT. Radiat Oncol. 2013;8:89.

125. Ayata HB, Güden M, Ceylan C, Kücük N, Engin K. Comparison of dose distributions and organs at risk (OAR) doses in conventional tangential technique (CTT) and IMRT plans with different numbers of beam in left-sided breast cancer. Rep Pract Oncol Radiother. 2011;16(3):95-102.

126. Liu H, Chen X, He Z, Li J. Evaluation of 3D-CRT, IMRT and VMAT radiotherapy plans for left breast cancer based on clinical dosimetric study. Comput Med Imaging Graph. 2016;54:1-5.

127. Michalski A, Atyeo J, Cox J, Rinks M, Morgia M, Lamoury G. A dosimetric comparison of 3D-CRT, IMRT, and static tomotherapy with an SIB for large and small breast volumes. Med Dosim. 2014;39(2):163-168.

128. Yin Y, Chen J, Sun T, et al. Dosimetric research on intensity-modulated arc radiotherapy planning for left breast cancer after breast-preservation surgery. Med Dosim. 2012;37(3):287-292.

129. Jo I, Kim SW, Son SH. Dosimetric evaluation of the skin-sparing effects of 3-dimensional conformal radiotherapy and intensity-modulated radiotherapy for left breast cancer. Oncotarget. 2016;8(2):3059-3063.

130. Fiorentino A, Ruggieri R, Giaj-Levra N, et al. Three-dimensional conformal versus intensity modulated radiotherapy in breast cancer treatment: is necessary a medical reversal? Radiol Med. 2017;122(2):146-153.
131. Gursel B, Meydan D, Ozbek N, Ofluoglu T. Dosimetric comparison of three different external beam whole breast irradiation techniques. Adv Ther. 2011;28(12):1114-1125.

132. Fogliata A, Bolsi A, Cozzi L. Critical appraisal of treatment techniques based on conventional photon beams, intensity modulated photon beams and proton beams for therapy of intact breast. Radiother Oncol. 2002;62(2):137-145.

133. Smith W, Menon G, Wolfe N, Ploquin N, Trotter T, Pudney D. IMRT for the breast: a comparison of tangential planning techniques. Phys Med Biol. 2010;55(4):1231-1241.

134. Tsuchiya K, Kinoshita R, Shimizu S, et al. Dosimetric comparison between intensity-modulated radiotherapy and standard wedged tangential technique for whole-breast radiotherapy in Asian women with relatively small breast volumes. Radiol Phys Technol. 2014;7(1):67-72.

135. Virén T, Heikkilä J, Myllyoja K, Koskela K, Lahtinen T, Seppälä J. Tangential volumetric modulated arc therapy technique for left-sided breast cancer radiotherapy. Radiat Oncol. 2015;10:79.

136. Chung MJ, Kim SH, Lee JH, Suh YJ. A Dosimetric comparative analysis of TomoDirect and three-dimensional conformal radiotherapy in early breast cancer. J Breast Cancer. 2015;18(1):57-62.

137. Ercan T, Igdem S, Alço G, et al. Dosimetric comparison of field in field intensity modulated radiotherapy technique with conformal radiotherapy techniques in breast cancer. Jpn J Radiol. 2010;28(4): 283-289.

138. Lin Y, Wang B. Dosimetric absorption of intensity-modulated radiotherapy compared with conventional radiotherapy in breast-conserving surgery. Oncol Lett. 2015;9(1):9-14.

139. Ahunbay EE, Chen GP, Thatcher S, et al. Direct aperture optimizationbased intensity-modulated radiotherapy for whole breast irradiation. Int J Radiat Oncol Biol Phys. 2007;67(4):1248-1258.

140. Aly MM, Glatting G, Jahnke L, Wenz F, Abo-Madyan Y. Comparison of breast simultaneous integrated boost (SIB) radiotherapy techniques. Radiat Oncol. 2015;10:139.

141. Baycan D, Karacetin D, Balkanay AY, Barut Y. Field-in-field IMRT versus 3D-CRT of the breast. Cardiac vessels, ipsilateral lung, and contralateral breast absorbed doses in patients with left-sided lumpectomy: a dosimetric comparison. Jpn J Radiol. 2012;30(10): 819-823.

142. Mansouri S, Naim A, Glaria L, Marsiglia H. Dosimetric evaluation of 3-D conformal and intensity-modulated radiotherapy for breast cancer after conservative surgery. Asian Pac J Cancer Prev. 2014;15(11):4727-4732.

143. Mayo CS, Urie MM, Fitzgerald TJ. Hybrid IMRT plans-concurrently treating conventional and IMRT beams for improved breast irradiation and reduced planning time. Int J Radiat Oncol Biol Phys. 2005;61(3):922-932.

144. Qi XS, Liu TX, Liu AK, et al. Left-sided breast cancer irradiation using rotational and fixed-field radiotherapy. Med Dosim. 2014;39(3):227-234.

145. Singla R, King S, Albuquerque K, Creech S, Dogan N. Simultaneousintegrated boost intensity-modulated radiation therapy (SIB-IMRT) in the treatment of early-stage left-sided breast carcinoma. Med Dosim. 2006;31(3):190-196.

146. Chen GP, Liu F, White J, et al. A planning comparison of 7 irradiation options allowed in RTOG 1005 for early-stage breast cancer. Med Dosim. 2015;40(1):21-25.

147. Yim J, Suttie C, Bromley R, Morgia M, Lamoury G. Intensity modulated radiotherapy and $3 \mathrm{D}$ conformal radiotherapy for whole breast irradiation: a comparative dosimetric study and introduction of a novel qualitative index for plan evaluation, the normal tissue index. $J$ Med Radiat Sci. 2015;62(3):184-191.

148. Lohr F, El-Haddad M, Dobler B, et al. Potential effect of robust and simple IMRT approach for left-sided breast cancer on cardiac mortality. Int J Radiat Oncol Biol Phys. 2009;74(1):73-80.

149. Peulen H, Hanbeukers B, Boersma L, et al. Forward intensitymodulated radiotherapy planning in breast cancer to improve dose homogeneity: feasibility of class solutions. Int J Radiat Oncol Biol Phys. 2012;82(1):394-400. 
150. Joo JH, Kim SS, Ahn SD, et al. Cardiac dose reduction during tangential breast irradiation using deep inspiration breath hold: a dose comparison study based on deformable image registration. Radiat Oncol. 2015;10:264.

151. Chi F, Wu S, Zhou J, et al. Dosimetric comparison of moderate deep inspiration breath-hold and free-breathing intensity-modulated radiotherapy for left-sided breast cancer. Cancer Radiother. 2015;19(3):180-186.

152. Rochet N, Drake JI, Harrington K, et al. Deep inspiration breath-hold technique in left-sided breast cancer radiation therapy: Evaluating cardiac contact distance as a predictor of cardiac exposure for patient selection. Pract Radiat Oncol. 2015;5(3):e127-e134.

153. Bruzzaniti V, Abate A, Pinnarò $P$, et al. Dosimetric and clinical advantages of deep inspiration breath-hold (DIBH) during radiotherapy of breast cancer. J Exp Clin Cancer Res. 2013;32:88.

154. Register S, Takita C, Reis I, Zhao W, Amestoy W, Wright J. Deep inspiration breath-hold technique for left-sided breast cancer: an analysis of predictors for organ-at-risk sparing. Med Dosim. 2015;40(1):89-95.

155. Osei E, Darko J, Fleck A, et al. Dosimetric evaluation of whole-breast radiation therapy: clinical experience. Med Dosim. 2015;40(4):355-365.

156. Vikström J, Hjelstuen MH, Mjaaland I, Dybvik KI. Cardiac and pulmonary dose reduction for tangentially irradiated breast cancer, utilizing deep inspiration breath-hold with audio-visual guidance, without compromising target coverage. Acta Oncol. 2011;50(1):42-50.

157. Osman SO, Hol S, Poortmans PM, Essers M. Volumetric modulated arc therapy and breath-hold in image-guided locoregional left-sided breast irradiation. Radiother Oncol. 2014;112(1):17-22.

158. Borst GR, Sonke JJ, den Hollander S, et al. Clinical results of imageguided deep inspiration breath hold breast irradiation. Int J Radiat Oncol Biol Phys. 2010;78(5):1345-1351.

159. Hepp R, Ammerpohl M, Morgenstern C, et al. Deep inspiration breathhold (DIBH) radiotherapy in left-sided breast cancer. Strahlenther Onkol. 2015;191(9):710-716.

160. Sung K, Lee KC, Lee SH, Ahn SH, Lee SH, Choi J. Cardiac dose reduction with breathing adapted radiotherapy using self respiration monitoring system for left-sided breast cancer. Radiat Oncol J. 2014;32(2):84-94.

161. Comsa D, Barnett E, Le K, et al. Introduction of moderate deep inspiration breath hold for radiation therapy of left breast: initial experience of a regional cancer center. Pract Radiat Oncol. 2014;4(5):298-305.

162. Lee HY, Chang JS, Lee IJ, et al. The deep inspiration breath hold technique using Abches reduces cardiac dose in patients undergoing left-sided breast irradiation. Radiat Oncol J. 2013;31(4):239-246.

163. Schönecker S, Heinz C, Söhn M, et al. Reduction of cardiac and coronary artery doses in irradiation of left-sided breast cancer during inspiration breath hold. Strahlenther Onkol. 2016;192(11):750-758.

164. Shim JG, Kim JK, Park W, et al. Dose-volume analysis of lung and heart according to respiration in breast cancer patients treated with breast conserving surgery. J Breast Cancer. 2012;15(1):105-110.

165. Tanguturi SK, Lyatskaya Y, Chen Y, et al. Prospective assessment of deep inspiration breath hold using 3-dimensional surface tracking for irradiation of left-sided breast cancer. Int J Radiat Oncol Biol Phys. 2015;93(3):E4.

166. Wang W, Purdie TG, Rahman M, Marshall A, Liu FF, Fyles A. Rapid automated treatment planning process to select breast cancer patients for active breathing control to achieve cardiac dose reduction. Int $J$ Radiat Oncol Biol Phys. 2012;82(1):386-393.

167. Yeung R, Conroy L, Long K, et al. Cardiac dose reduction with deep inspiration breath hold for left-sided breast cancer radiotherapy patients with and without regional nodal irradiation. Radiat Oncol. 2015;10:200.

168. Reardon KA, Read PW, Morris MM, Reardon MA, Geesey C, Wijesooriya K. A comparative analysis of 3D conformal deep inspiratorybreath hold and free-breathing intensity-modulated radiation therapy for left-sided breast cancer. Med Dosim . 2013;38(2):190-195.

169. Frazier RC, Vicini FA, Sharpe MB, et al. Impact of breathing motion on whole breast radiotherapy: a dosimetric analysis using active breathing control. Int J Radiat Oncol Biol Phys. 2004;58(4):1041-1047.
170. Rodríguez N, Sanz X, Dengra J, et al. Five-year outcomes, cosmesis, and toxicity with 3-dimensional conformal external beam radiation therapy to deliver accelerated partial breast irradiation. Int J Radiat Oncol Biol Phys. 2013;87(5):1051-1057.

171. Oliver M, Chen J, Wong E, Van Dyk J, Perera F. A treatment planning study comparing whole breast radiation therapy against conformal, IMRT and tomotherapy for accelerated partial breast irradiation. Radiother Oncol. 2007;82(3):317-323.

172. Kumar R, Sharma SC, Kapoor R, Singh R, Bhardawaj A. Dosimetric evaluation of $3 \mathrm{D}$ conformal accelerated partial-breast irradiation vs. whole-breast irradiation: a comparative study. Int J Appl Basic Med Res. 2012;2(1):52-57.

173. Baglan KL, Sharpe MB, Jaffray D, et al. Accelerated partial breast irradiation using 3D conformal radiation therapy (3D-CRT). Int $J$ Radiat Oncol Biol Phys. 2003;55(2):302-311.

174. Fernández-Lizarbe E, Montero A, Polo A, et al. Pilot study of feasibility and dosimetric comparison of prone versus supine breast radiotherapy. Clin Transl Oncol. 2013;15(6):450-459.

175. Buijsen J, Jager JJ, Bovendeerd J, et al. Prone breast irradiation for pendulous breasts. Radiother Oncol. 2007;82(3):337-340.

176. Coon AB, Dickler A, Kirk MC, et al. Tomotherapy and multifield intensity-modulated radiotherapy planning reduce cardiac doses in left-sided breast cancer patients with unfavorable cardiac anatomy. Int J Radiat Oncol Biol Phys. 2010;78(1):104-110.

177. Selvaraj RN, Beriwal S, Pourarian RJ, et al. Clinical implementation of tangential field intensity modulated radiation therapy (IMRT) using sliding window technique and dosimetric comparison with 3D conforma therapy (3DCRT) in breast cancer. Med Dosim. 2007;32(4):299-304.

178. Jöst V, Kretschmer M, Sabatino M, et al. Heart dose reduction in breast cancer treatment with simultaneous integrated boost. Strahlenther Onkol. 2015;191(9):734-741.

179. Haciislamoglu E, Colak F, Canyilmaz E, et al. Dosimetric comparison of left-sided whole-breast irradiation with 3DCRT, forward-planned IMRT, inverse-planned IMRT, helical tomotherapy, and volumetric arc therapy. Phys Med. 2015;31(4):360-367.

180. Zhang F, Zheng M. Dosimetric evaluation of conventional radiotherapy, 3-D conformal radiotherapy and direct machine parameter optimisation intensity-modulated radiotherapy for breast cancer after conservative surgery. J Med Imaging Radiat Oncol. 2011;55(6):595-602.

181. Wiant D, Wentworth S, Liu H, Sintay B. How important is a reproducible breath hold for deep inspiration breath hold breast radiation therapy? Int J Radiat Oncol Biol Phys. 2015;93(4):901-907.

182. D’Agostino GR, Diletto B, Mantini G, et al. Reducing heart dose during left breast cancer radiotherapy: comparison among 3 radiation techniques. Tumori. 2016;102(2):184-189.

183. Kathpal M, Tinnel B, Sun K, et al. Deep inspiration breath hold with electromagnetic confirmation of chest wall position for adjuvant therapy of left-sided breast cancer: technique and accuracy. Pract Radiat Oncol. 2016;6(5):e195-e202.

184. Stranzl H, Zurl B. Postoperative irradiation of left-sided breast cancer patients and cardiac toxicity. Strahlenther Onkol. 2008;184(7): 354-358.

185. Lin A, Sharieff W, Juhasz J, Whelan T, Kim DH. The benefit of deep inspiration breath hold: evaluating cardiac radiation exposure in patients after mastectomy and after breast-conserving surgery. Breast Cancer. 2017;24(1):86-91.

186. Schönecker S, Walter F, Freislederer P, et al. Treatment planning and evaluation of gated radiotherapy in left-sided breast cancer patients using the Catalyst ${ }^{\mathrm{TM}} /$ Sentinel ${ }^{\mathrm{TM}}$ system for deep inspiration breath-hold (DIBH). Radiat Oncol. 2016;11(1):143.

187. Pedersen AN, Korreman S, Nyström H, Specht L. Breathing adapted radiotherapy of breast cancer: reduction of cardiac and pulmonary doses using voluntary inspiration breath-hold. Radiother Oncol. 2004;72(1):53-60.

188. Bensaleh S, Bezak E, Borg M. Review of MammoSite brachytherapy: advantages, disadvantages and clinical outcomes. Acta Oncol. 2009;48(4):487-494. 


\section{Publish your work in this journal}

Cancer Management and Research is an international, peer-reviewed open access journal focusing on cancer research and the optimal use of preventative and integrated treatment interventions to achieve improved outcomes, enhanced survival and quality of life for the cancer patient. The manuscript management system is completely online and includes a very quick and fair peer-review system, which is all easy to use. Visit http://www.dovepress.com/testimonials.php to read real quotes from published authors.

Submit your manuscript here: https://www.dovepress.com/cancer-management-and-research-journal 